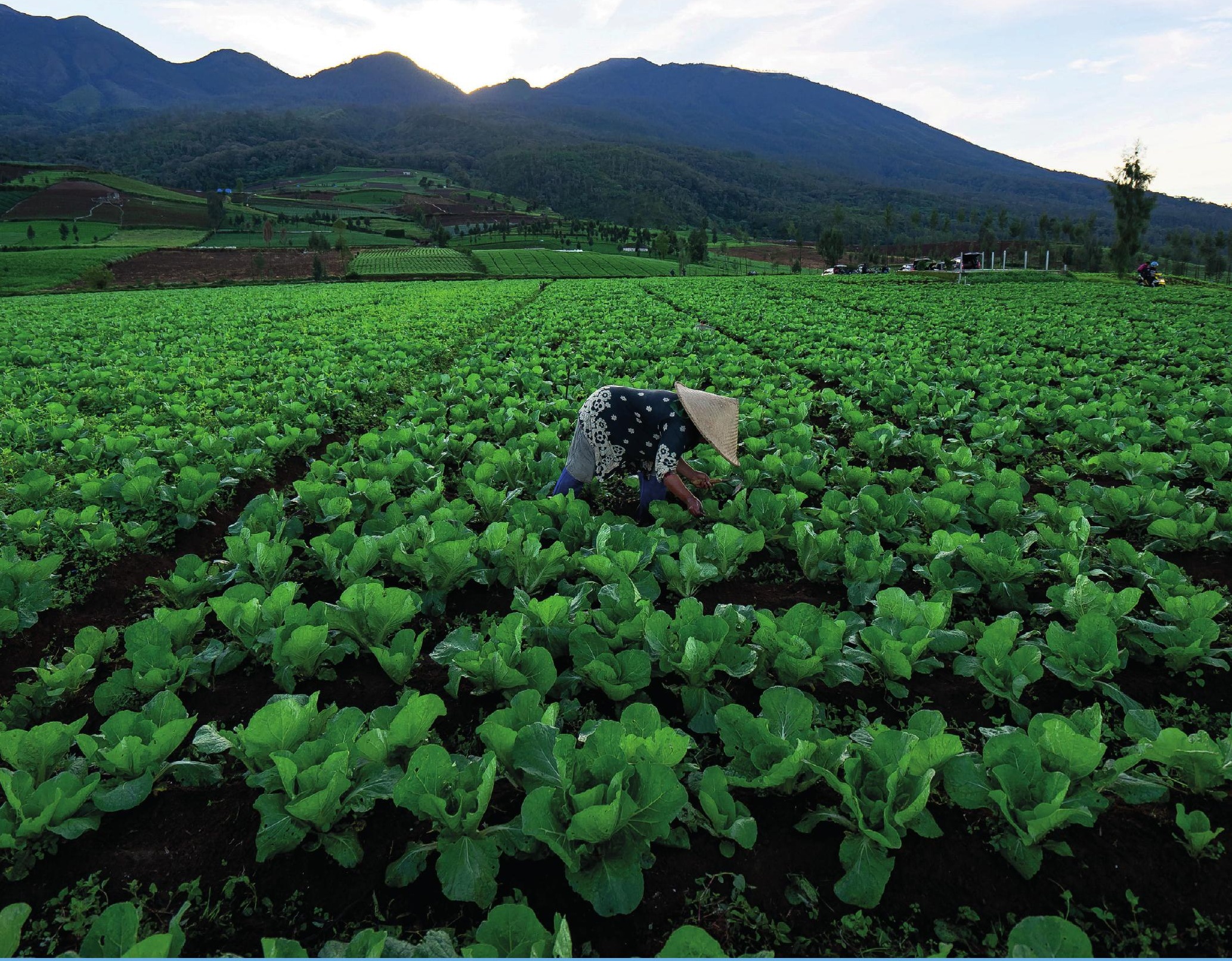

\title{
Key findings and lessons from Dutch publicly funded horticulture initiatives in low- and middle-income countries
}

Valuable Vegetables Synthesis Paper

Indira Moreno-Echeverri, Johann Bonnand, Salome Boyd and Edwin van der Maden 



\section{Key findings and lessons from Dutch publicly funded horticulture initiatives in low- and middle-income countries}

Valuable Vegetables Synthesis Paper

Indira Moreno-Echeverri ${ }^{1}$, Johann Bonnand ${ }^{2}$, Salome Boyd ${ }^{1}$, Edwin van der Maden $^{1}$

1 Wageningen University \& Research, Wageningen Centre for Development Innovation

2 Wageningen University \& Research, Wageningen Plant Research Field Crops

This research was commissioned by the Food \& Business Knowledge Platform in the context of the "Valuable Vegetables" learning initiative. 
Indira Moreno-Echeverri, Johann Bonnand, Salome Boyd and Edwin van der Maden, 2020. Key findings and lessons from Dutch publicly funded horticulture initiatives in low- and middle-income countries; Valuable Vegetables Synthesis Paper. Wageningen Centre for Development Innovation, Wageningen University \& Research. Report WCDI-20-115. Wageningen.

This synthesis paper was commissioned by the Food \& Business Knowledge Platform in the context of the Valuable Vegetables learning initiative, which is a collaboration between AgriProFocus and the Dutch Ministries of Foreign Affairs and Agriculture, Nature and Food Quality. The synthesis paper provides an inventory of Dutch publicly funded horticulture sector initiatives since 2009 . Then, using a quick analysis of eight representative horticultural projects, it summarizes key findings and formulates general lessons learned from these horticulture sector programmes, projects and collaborations in lowand middle-income countries. This synthesis study is intended to serve as background and input for future Valuable Vegetables learning activities, supporting its overall objective: To learn from ongoing and completed programmes in the horticulture sector and to communicate the lessons learned with the wider food and nutrition security network, in order to both improve and innovate in approaches, practices and policies and to contribute to food and nutrition security.

Keywords: vegetables, horticulture sector, horticulture projects, sector transformation, sector performance, low- and middle-income countries, food and nutrition security

\section{Acknowledgements}

The authors would like to express their gratitude to those who have contributed to this study and report. Firstly, we would like to thank the project leaders of the eight selected projects as well as other people who responded positively to the request for information. We would like to thank Wim Simonse (Woord en Daad), Huib Hengsdijk (WUR), Karin Kramers (RVO), Elijah Mwashayenyi (East-West Seed), Gerrit Holtland (SNV) and Irene Koomen (WUR) for their time and willingness to share their experiences, insights and project documents with us.

In addition, we would like to thank everyone who contributed in other ways to the completion of this report, in particular Irene Koomen (WUR), Anne Elings (WPR), Flip van Koesveld (WPR), Yeray Saavedra (WCDI) and Nicole Metz (F\&BKP), for their guidance, views and for reviewing the draft version of this report. We also thank Heleen Bos (Rijk Zwaan), Frank Joosten (Advance Consulting) and Jan van Saanen (RVO), the external reviewers of this report, for validation of findings and providing additional feedback. Finally, we would like to thank Ruth Davies for editing of the report.

While this study was being undertaken, the COVID-19 pandemic broke out. We are all aware this has already had and will continue to have a large impact on global food systems, including the horticulture sector. The pandemic will undoubtedly affect how we conduct horticulture projects in the future.

This report can be downloaded for free at https://doi.org/10.18174/524397 or at www.wur.eu/cdi (under publications) or at https://knowledge4food.net/key-findings-lessons-dutch-public-fundedhorticulture-initiatives-Imics.

2020 Wageningen Centre for Development Innovation, part of the Stichting Wageningen Research. P.O. Box 88, 6700 AB Wageningen, The Netherlands. T + 31 (0)317 4868 00, E info.cdi@wur.nl, www.wur.eu/cdi.

\section{(cc) BY-NC}

The Wageningen Centre for Development Innovation uses a Creative Commons Attribution 4.0 (Netherlands) licence for its reports.

The user may copy, distribute and transmit the work and create derivative works. Third-party material that has been used in the work and to which intellectual property rights apply may not be used without prior permission of the third party concerned. The user must specify the name as stated by the author or licence holder of the work, but not in such a way as to give the impression that the work of the user or the way in which the work has been used are being endorsed. The user may not use this work for commercial purposes.

The Wageningen Centre for Development Innovation accepts no liability for any damage arising from the use of the results of this research or the application of the recommendations.

Confidential | Report WCDI-20-115 | ISSN 0000-0000 | ISBN/EAN 000-00-0000-000-0

Photo cover: Shutterstock.com 


\section{Contents}

List of abbreviations and acronyms

$\begin{array}{lr}\text { Summary } & 7\end{array}$

1

Introduction

2 Methodology

11

2.1 The horticulture initiatives $\quad 11$

2.2 Selected case studies $\quad 11$

2.3 Sector transformation approach $\quad 12$

$\begin{array}{ll}2.4 & \text { Limitations of the study } \\ \end{array}$

$3 \quad$ Overview of Dutch publicly funded horticulture initiatives

4

Key findings and lessons learned $\quad 19$

4.1 Competitiveness 19

4.2 Profitability $\quad 21$

$\begin{array}{lll}4.3 & \text { Resilience } & 21\end{array}$

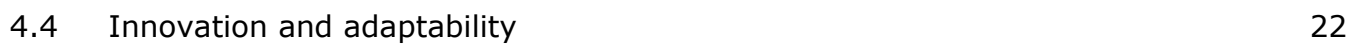

$\begin{array}{lll}4.5 & \text { Sustainability } & 24\end{array}$

$\begin{array}{ll}4.6 & \text { Exit strategy }\end{array}$

$\begin{array}{lll}4.7 & \text { Inclusiveness } & 26\end{array}$

$\begin{array}{lll}4.8 & \text { Transparency } & 26\end{array}$

$\begin{array}{llr}5 & \text { Discussion and conclusions } & 29\end{array}$

$\begin{array}{lr}\text { References } & 33\end{array}$

$\begin{array}{lll}\text { Appendix } 1 & \text { Overview of projects and programmes per country } & 35\end{array}$

$\begin{array}{lll}\text { Appendix } 2 & \text { Analysis of selected projects } & 37\end{array}$ 



\section{List of abbreviations and acronyms}

$\begin{array}{ll}\text { F\&BKP } & \text { Food \& Business Knowledge Platform } \\ \text { FFS } & \text { Farmer Field School } \\ \text { GAP } & \text { good agricultural practices } \\ \text { GGL } & \text { Ghana Green Label } \\ \text { IPM } & \text { integrated pest management } \\ \text { LMIC } & \text { low- and middle-income country } \\ \text { PMC } & \text { product marketing combination } \\ \text { PSI } & \text { private sector investment } \\ \text { RVO } & \text { Netherlands Enterprise Agency } \\ \text { SDG } & \text { Sustainable Development Goal } \\ \text { SEVIA } & \text { Seeds of Expertise for the Vegetable Industry of Africa } \\ \text { SSP } & \text { Spray Service Providers } \\ \text { TAHA } & \text { Tanzanian Horticulture Association } \\ \text { TOT } & \text { Training of trainers } \\ \text { WCDI } & \text { Wageningen Centre for Development Innovation, Wageningen University \& } \\ & \text { Research } \\ \text { WPR } & \text { Wageningen Plant Research } \\ \text { WUR } & \text { Wageningen University \& Research }\end{array}$




\section{Summary}

The horticulture sector has received increasing attention in recent years, from both public and private sectors and from the angle of business development and development cooperation. This focus is especially due to the sector's potential contribution to (inclusive) business development, profit and income generation, employment creation, enhanced food and nutrition security and economic growth. As such it has the potential to contribute to many of the Sustainable Development Goals (SDGs).

Within this context, the Food \& Business Knowledge Platform, under its Valuable Vegetables initiative, commissioned Wageningen University \& Research (WUR) to conduct an initial synthesis study to collect the key findings from Dutch publicly funded horticulture initiatives in LMICs. This synthesis paper collected these findings with the aim of summarizing general lessons learned and contributing to improved policy and practice of future horticulture development initiatives. The overall objective of the Valuable Vegetables initiative is to learn from ongoing and completed programmes in the horticulture sector and to communicate the lessons learned with the wider food and nutrition security network.

The first part of this report provides an inventory of 160 Dutch publicly funded horticulture sector initiatives since 2009 in Asia, Africa, Latin America and the Middle East with a budget exceeding $€ 10,000$. Dutch public institutes contributed $€ 211$ million to these projects through a variety of funding mechanisms. These projects fall into four categories: 1) studies, fairs, events and trade missions; 2) value chain and sector development; 3) education, capacity strengthening, training and demonstration; and 4) private sector investment. These 160 projects provide an extensive picture of Dutch investment in the horticulture sector.

The second part of the report consists of a quick analysis of eight selected projects to extract key findings and formulate general lessons learned by means of reviewing project documentation. In several cases, interviews with project leaders were conducted to gain more in-depth understanding of the outcomes or impact and the corresponding lessons that could be drawn. In the analysis, questions were asked about what strengthened the capacities of (current and future) horticulture entrepreneurs, which interventions/investments fostered the creation and sustainability of horticulture businesses and investments, how interventions improved the policy/enabling environment for sector transformation, how changes in the enabling environment influenced transformation processes in the sector, which knowledge and innovation processes facilitated the development of the sector and which sector interventions had a measurable effect on other SDGs (e.g. food and nutrition security, gender, climate resilience).

The sector transformation model developed by Aidenvironment and its key components of sector performance were taken as a basis for the quick analysis of the eight selected horticulture projects, which offered a structured holistic methodology for the analysis. The sector performance components were slightly adapted to serve the purpose of this study.

It is important to note that this study, through analysing the key findings of a selection of representative projects, aims to provide initial background and input for future Valuable Vegetables learning activities. However, it is not an impact study or evaluation of Dutch publicly funded horticulture projects and programmes. It is qualitative in nature, providing general lessons from horticulture initiatives to initiate further discussions and learnings and does not provide detailed quantification or evaluation of outcomes and impacts. Therefore, the lessons learned have not been weighted against their contribution to sector development.

The eight projects analysed have all contributed to development of the horticulture sector in LMICs, each at different scales and with different impact. The analysis generated interesting lessons for future interventions and investments and raised a number of remaining questions and challenges. Firstly, the creation of linkages, partnerships - particularly visible between farmers and service or input providers 
and information flow between various actors within the value chain or in the horticulture sector has fostered adoption of technologies and created better trust among actors.

Secondly, evidence-based and practice-oriented capacity strengthening, peer-to-peer learning and face-to-face interactions appeared to be key for the adoption of new technologies and good agricultural practices. However, with regard to training approaches, it is still not clear to what extent relatively short training interventions can bring behavioural change, and how continuous learning can be incentivized.

Using the selected sector transformation components was an effective approach to gather lessons on several key aspects of the projects, though not all aspects. At times, there was a lack of clear data and indicators on, for example, quantifying the impact with respect to the profitability component. Regarding the resilience, sustainability (beyond the environmental dimension) and inclusiveness components, we noted that while projects were working on these elements, few projects seem to have worked holistically or to have been designed to address these issues. For example, many of the end beneficiaries of these projects were smallholder farmers, including women. However, in most cases no clear inclusiveness objectives or strategies had been defined, apart from reaching or participation of a targeted number.

Another observation was that projects often do not have their exit strategies clearly defined; in particular, the involvement, roles and responsibilities of public and private sector actors in continuing to develop the sector after the project finishes is not clear. Despite the suggestion of positive developments in the horticulture sector, some projects still have a limited reach that is considered insufficient to take sector transformation to scale. There is no doubt that other sector actors, both public and private, will have to intensify their efforts and commitment to continue improving the horticulture sector after these projects end. For example, while public bodies and authorities are considered important actors for helping projects develop at local levels, they have often proved to cause delay at higher levels due to the bureaucratic nature of these institutions.

In general, and in line with ongoing discussions about development cooperation and horticulture sector development, implementing organizations and public and private actors are looking for ways to achieve more systemic impact at sector and/or food system level. Future projects and programmes are being challenged to address these systemic impact issues in their designs and approaches. As not all project leaders of the eight selected horticulture projects agreed on the general findings of the analysis, the outcomes of this synthesis paper need to be read as the independent insights of the authors. This report is meant to start up discussions based on, and challenging, the insights - so these can be further explored and analysed and thereupon serve to improve action in the sector. 


\section{Introduction}

Population growth coupled with rapid urbanization, economic growth and an emerging middle class increases demand for horticulture products, both in developing countries and emerging economies. These trends have made the horticulture sector of interest and importance to low- and middle-income countries (LMICs) due to the sector's potential contribution to (inclusive) business development, profit and income generation, employment creation, enhanced food and nutrition security and economic growth, and thus its potential to contribute to healthy, sustainable and inclusive foods systems and the sustainable development goals (SDGs).

The Dutch government promotes an integrated foreign trade and development cooperation policy, connecting foreign trade, development support, private sector development and international private sector investments. This has put horticulture high on the agenda as a sector for development cooperation and more Dutch government international horticulture projects, programmes and partnerships. Contributing to a stronger horticulture sector in LMICs is currently among the key strategies of the Dutch development agenda for global food and nutrition security.

Horticulture is also seen as an opportunity for investment in LMICs by Dutch private companies. It offers opportunities for young and female entrepreneurs, can boost transformation in the general agriculture sector and can contribute to advancing nutrition outcomes and climate resilience.

During the past decade, therefore, a range of Dutch public and private initiatives and investments have been realized in the sector in partnership with sector actors in Africa, Asia and other regions. As there is clear interest in continuing and expanding investments in the horticulture sector in LMICs, there is also a need to build on the key findings and lessons learned so far. The Valuable Vegetables initiative, implemented by the Food \& Business Knowledge Platform (F\&BKP), aims to facilitate and disseminate such systematic learnings.

The overall objective of the Valuable Vegetables initiative is to learn from ongoing and completed programmes in the horticulture sector and to communicate the lessons learned with the wider food and nutrition security network. The initiative offers key players in the horticulture sector a platform to share, learn and exchange knowledge and experiences, and to develop, implement and scale innovative solutions for challenges in the sector. The aim is to improve policy and practice through collective action and to contribute to food and nutrition security.

Within this context the F\&BKP commissioned Wageningen University \& Research (WUR) to conduct an initial synthesis study to collect the key findings from Dutch publicly funded horticulture initiatives in LMICs and to summarize general lessons learned to serve as background and input for future Valuable Vegetables learning activities.

This synthesis has collected the key findings from horticulture sector programmes, projects and collaborations funded by the Dutch government through the Ministry of Foreign Affairs and the Netherlands Enterprise Agency (RVO) in LMICs, with the aim of summarizing lessons learned. It provides an inventory of Dutch publicly funded projects in the horticulture sector since 2009 in Asia, Africa, Latin America and the Middle East and includes a quick analysis of eight selected projects, which were used to formulate a set of general lessons learned.

This synthesis study is intended to serve as background and input for future Valuable Vegetables learning activities and supports the overall objective of the Valuable Vegetables initiative: To learn from ongoing and completed programmes in the horticulture sector and to communicate the lessons learned with the wider food and nutrition security network, in order to both improve and innovate in approaches, practices and policies. 
The methodology for the report is given in Chapter 2. Chapter 3 provides an overview of the Dutch publicly funded horticulture projects in LMICs: their focus areas, budgets and the regions in which they have been implemented. Chapter 4 gives a quick analysis of the eight selected projects, uncovers the key findings and formulates general lessons learned. In the appendices an overview by country of the identified projects can be found, along with the analysis reports for each of the eight selected cases from which lessons learned have been extracted. 


\section{Methodology}

\subsection{The horticulture initiatives}

For the purpose of this synthesis study, an extensive overview of $160^{1}$ Dutch publicly funded horticulture initiatives in LMICs was compiled, based on those funded by the government of the Netherlands through the Ministry of Foreign Affairs and the Netherlands Enterprise Agency (RVO). These projects and programmes have been retrieved from the RVO database (RVO, 2020) and from the Budget Foreign Trade and Development Cooperation (Ministry of Foreign Affairs, 2020) and the Dutch Development Results web pages (https://www.dutchdevelopmentresults. nl). This resulted in a list of 160 projects, selected based on the criteria of being:

- focused on or related to horticulture

- located in Latin America, Africa, the Middle East or Asia

- with a budget exceeding $€ 10,000$

- with start dates from 2009 onwards.

In order to simplify and structure the analysis, the 160 projects have been divided into four categories, based on their characteristics and objectives:

1. Studies, fairs, events and trade missions: These include all the scoping missions, fairs and other events funded by the Netherlands that have taken place in LMICs. Background studies on horticultural value chains or sectors and projects with limited budgets have also been included under this category.

2. Value chain and sector development: These include all the projects that have contributed to the development of horticultural value chains and/or the horticulture sector, addressing multiple stages (from production to consumer) and levels (from farmer up to policy level), including a variety of targeted actors and stakeholders (public and private). These projects are centred around the development of the value chain and the sector as a whole through a variety of (interlinked) interventions at multiple levels but within the context of a different theoretical framework $^{2}$.

3. Education, capacity strengthening, training and demonstration: These include the projects where the main focus is on capacity strengthening and knowledge transfers.

4. Private sector investments: These include "subsidy programmes supporting innovative investment projects in developing countries" (RVO, 2020) which have been subsidized under the private sector investment (PSI) subsidy mechanism. ${ }^{3}$

\subsection{Selected case studies}

From the extensive overview of 160 Dutch publicly funded horticulture initiatives, 10 projects were initially selected to represent the full set based on geographical location, project type, scope and budget amount. As the focus for this study was on projects with direct investment in or contribution to the horticulture sector, projects with a focus on studies, fairs, events and trade missions were not included in the representative selection because of their limited scope and budgets and the low

1 These 160 projects provide an extensive picture of Dutch investments in the horticulture sectors of LMICs; although the study team has endeavoured to make the list as complete as possible, some projects may still be missing in this overview (see section 2.4). The list of projects by country is given in Appendix 1.

2 The difference between these theoretical frameworks and the opportunities and risks of each of these are not explicitly addressed in this synthesis paper. These may be a subject for further dialogue among sector stakeholders, which Valuable Vegetables initiative may facilitate.

3 This grant allocated by the Ministry of Foreign Affairs is used by an applicant company to develop (and pilot) investments in cooperation with a local business partner in LMICs. The applicant is also required to bring 40-50\% of the co-funding. In this report, only the funds allocated by RVO are indicated. 
relevance of the lessons learned from them for this project. Additionally, due to difficulty in accessing information (see section 2.4) two projects were excluded, leaving eight that were analysed.

Table 1 Selected projects

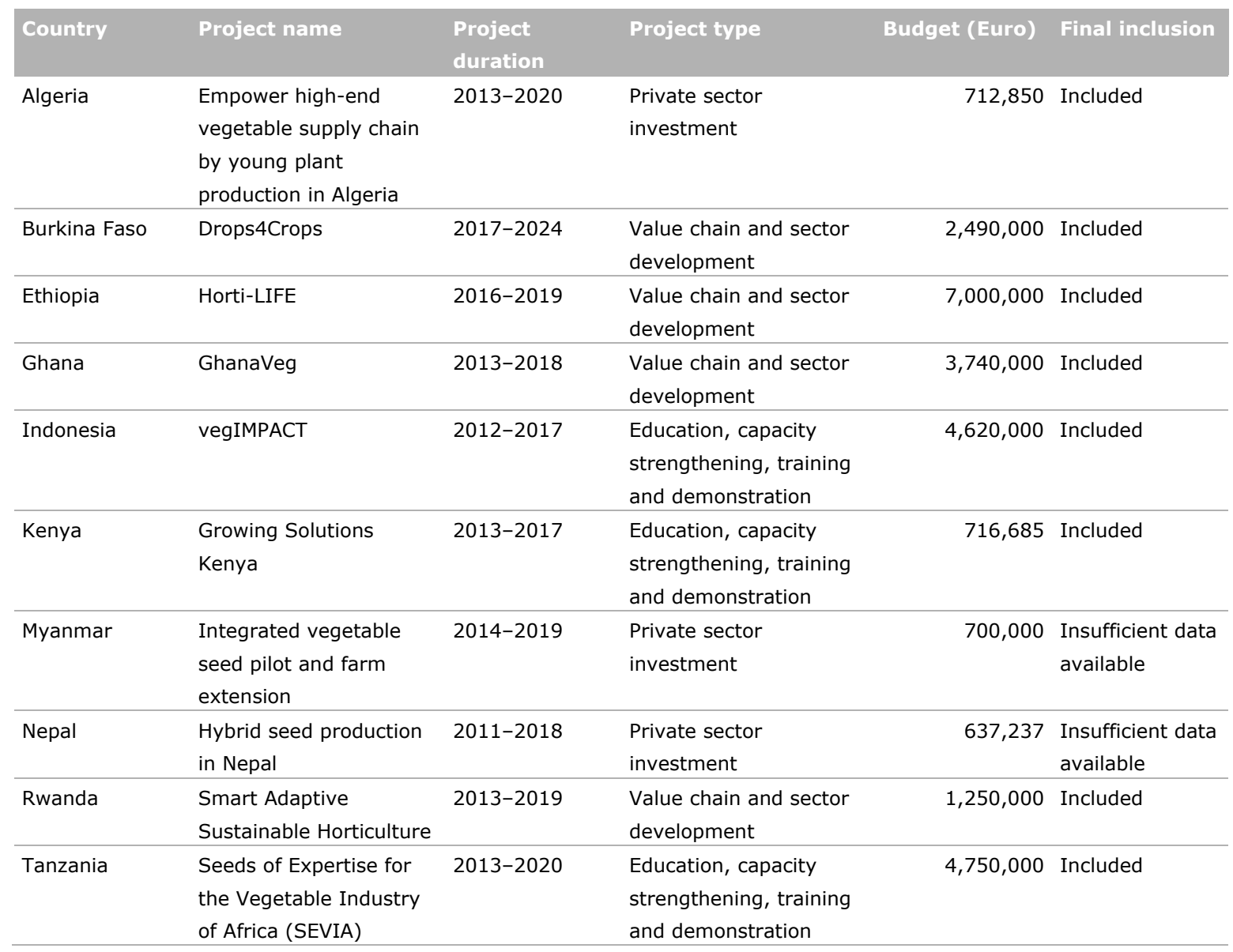

The projects were first analysed through study of their available reports and literature, then interviews and/or email exchanges were conducted with the project leaders. Reflection questions were used to look at the different angles of project outcomes and impacts at different scales and levels:

a. What worked to strengthen the capacities of (current and future) horticulture entrepreneurs?

b. Which interventions/investments fostered the creation and sustainability of horticulture businesses and investments (SMEs and other national or international companies)?

c. How did interventions effectively improve the policy/enabling environment for horticulture sector transformation? How did changes in the enabling environment effectively influence the transformation processes in the horticulture sector?

d. Which knowledge and innovation processes facilitated the development of the horticulture sector?

e. Which horticulture sector interventions had a measurable effect on other SDGs (e.g. food and nutrition security, gender, climate resilience)?

The more detailed analysis of the eight projects can be found in Appendix 2. These reports have been validated by the project leaders of the respective projects.

\subsection{Sector transformation approach}

Population growth, urbanization and economic development in LMICs are leading to a growing middle class that is increasing demand for horticultural products around the world, and will continue to do so in the coming decades. Since the potential of this sector has not yet been reached in many countries, it now has the attention of many organizations, including the governments that fund development 
programmes. Horticulture is one of the priority sectors of the Dutch food and nutrition security agenda (Ministry of Foreign Trade and Development Cooperation, 2018). The focus of the projects is on supporting the agenda of transformation from aid to trade, and the horticulture sector is seen as an investment opportunity for Dutch companies, inclusive business development, income generation or employment creation. The programmes aim to strengthen food and nutrition security, achieve SDGs and complete the development of healthy, sustainable and inclusive food systems in these - often still vulnerable - countries.

Consequently, the set of programmes funded by the Dutch government is diverse, with a variety of scopes and objectives. It was therefore important to use a model that allows the lessons learned in the projects to be clustered while giving some insights into the extent to which the projects have contributed to sector transformation. To provide this structure, the key elements of sector performance in the sector transformation model developed by Aidenvironment (Molenaar et al., 2015; Molenaar et al., 2017) were used as a basis for the quick analysis of the selected horticulture projects (see text box).

Indicators of sector performance

1. Competitive: in price and quality

2. Profitable: to farmers, workers and supply chain actors

3. Resilient: to price volatility and climate variability

4. Innovative and adaptive: to market trends

5. Sustainable: protects the environment, respects labour rights and applies fair trading practices

6. Inclusive: to the most vulnerable to participate

7. Resistant to rent seeking: elite capture and red-tape

8. Transparent: in trade flows and information

Source: Molenaar et al., 2017

This report is not an in-depth analysis of the performance of the horticulture sector in LMICs; rather, it uses the performance components from the sector transformation model to provide a structured and holistic approach for the quick analysis of the eight selected projects.

In order to cluster the lessons learned, and to serve the purpose of this study, some sector performance components were slightly adapted, removed or added (see Table 2); for example, the components "resistance to rent-seeking" and "legality" have been excluded since the scope of the majority of the projects did not cover those areas. The "exit strategy" component has been added as projects have an end date but outcomes might continue to have impact in the longer term. 


\begin{tabular}{|c|c|}
\hline Component & Definition \\
\hline Competitiveness & $\begin{array}{l}\text { This refers to the medium- to long-term ability of an actor within the horticulture sector to increase } \\
\text { productivity and/or lower costs in a sustainable way and deliver goods and services in the time, } \\
\text { place, form and quality sought by the targeted customer segment(s) at prices as good as or lower } \\
\text { than those of other potential suppliers, while earning a reasonable profit and paying at least } \\
\text { opportunity cost of resources employed (Dijkxhoorn et al., 2019). }\end{array}$ \\
\hline Resilience & $\begin{array}{l}\text { This refers to the capacity of the horticulture sector to absorb disturbance and reorganize while } \\
\text { undergoing change so as to still retain essentially the same function, structure and identity (Adger } \\
\text { et al., 2011), as well as the capacity of the sector to absorb economic, social, environmental and } \\
\text { institutional shocks and stresses including unexpected weather events, climate change, price } \\
\text { volatility, market risks and other challenges that may undermine the performance of the sector. }\end{array}$ \\
\hline $\begin{array}{l}\text { Innovation and } \\
\text { adaptability }\end{array}$ & $\begin{array}{l}\text { Innovation refers to the capability of the horticulture sector to respond to market dynamics, to add } \\
\text { value and to differentiate products (e.g. based on quality, sustainability, social responsibility, } \\
\text { certification); adaptability refers to the introduction of innovations in the horticulture sector and the } \\
\text { capacity of the targeted beneficiaries to benefit from them. }\end{array}$ \\
\hline Sustainability & $\begin{array}{l}\text { This refers to the capability of the horticulture sector to be environmentally non-degrading, } \\
\text { technologically appropriate, economically viable and socially acceptable, thus covering all three } \\
\text { dimensions of sustainability: social, environmental and economic in a way that ensures the } \\
\text { attainment and continued satisfaction of human needs for present and future generations (adapted } \\
\text { from } \mathrm{FAO}^{4} \text { ). }\end{array}$ \\
\hline Transparency & $\begin{array}{l}\text { This refers to the ability to be open and deliver relevant information (e.g. relevant actors, } \\
\text { production locations, trade flows, market information, regulatory information, farm performance) } \\
\text { across different stakeholders and social groups for the benefit of those groups. }\end{array}$ \\
\hline
\end{tabular}

Source: Adapted from Molenaar et al, 2017

\subsection{Limitations of the study}

We aimed to develop an overview and inventory of all Dutch publicly funded horticulture projects in LMICs since 2009 by reviewing extensive online databases (Ministry of Foreign Affairs, 2020; RVO, 2020). However, the databases did not clearly distinguish horticultural projects from other projects. Therefore, one limitation of this study is that some projects may have been overlooked that did focus on horticulture, so the inventory of projects might be incomplete. Other projects, such as the 3R Kenya project, also focus on multiple sectors. For such projects, it was not always possible to clearly define what budget was allocated to the horticultural component; in such cases the entire budget was counted for the purposes of this study.

It is important to note that the categorization of projects (Chapter 3) was challenging, as there are no clear boundaries between the categories listed. "Studies, fairs, events and trade missions" refers mostly to projects with limited budgets $(<€ 100 \mathrm{~K})$ and scope. "PSI programmes" are projects with specific organization and funding characteristics, and are therefore easier to categorize. The categories

4 See: http://www.fao.org/sustainability/en/ 
"value chain and sector development" and "education, capacity strengthening, training and demonstration" were difficult to separate, as many projects include the development of a part of the value chain with capacity-strengthening interventions. Projects with a clear and main focus on capacity strengthening were categorized under the "education, capacity strengthening, training and demonstration", while others with a more distinct value chain or sector approach were included under "value chain and sector development".

Furthermore, for the description of lessons learned (Chapter 4), the key challenges and limitations were related to the availability and quality of information. Some reports did not include any lessons learned during the projects, and some reports were not publicly available. Due to the scarce availability of information, the challenge of contacting project leaders, the lack of willingness to contribute to this study and the time restrictions, two case studies had to be excluded from the initial selection of 10 projects. Additionally, some interviews had to be carried out with project leaders to collect further insights about the lessons learned, but the leaders for the eight selected projects were not all available or in a position to share key learnings to enrich the findings from the available reports. Therefore, some of the important key findings and lessons might not have been incorporated in this synthesis report. Documentation of lessons learned in projects is limited, and sharing of project results is not common practice. Also, clients and funding providers do not always request project implementers to report directly on lessons learned.

Finally, limitations were found during the clustering, analysis and formulation of the general lessons learned while categorizing them into the different components of sector transformation. This was challenging because some learnings were very specific to a particular context, while other interventions revealed learnings that could apply to more than one component of sector transformation. For instance, what worked well in regards to reducing pesticide use could be categorized under "resilience" or "sustainability". In addition, as this study is intended as an initial quick analysis, deeper follow-up on projects would be necessary to assess the real impacts on possible sector changes and transformations to more accurately draw lessons from these projects.

Nevertheless, this report does provide initial and valuable background to initiate those deeper discussions on projects or around certain topics. This synthesis study, as such, is part of the broader learning initiative of Valuable Vegetables, which facilitates further exchange and learning among sector professionals on the findings of this study and on their own cases, experiences and (tacit) knowledge. 


\section{Overview of Dutch publicly funded horticulture initiatives}

The inventory of Dutch publicly funded horticulture initiatives in LMICs resulted in an overview of 160 projects and programmes, implemented in 47 different countries.

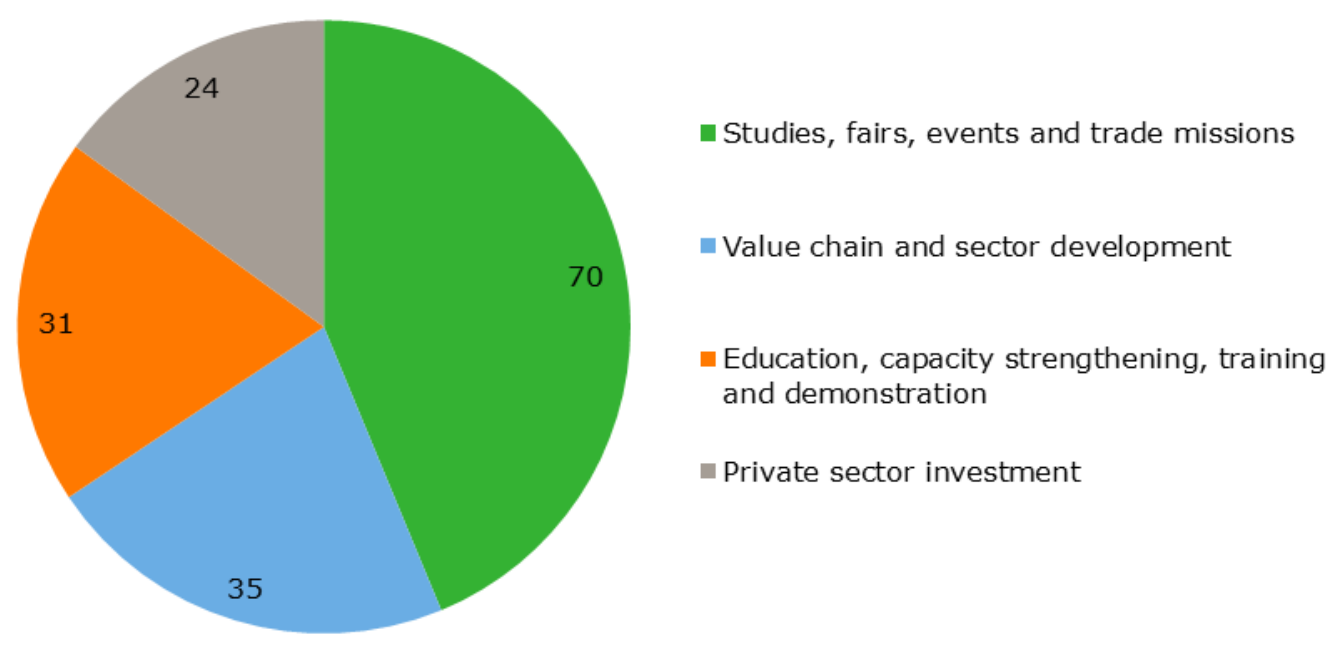

Figure $1 \quad$ Number of projects per project type

As shown in Figure 1, a significant proportion of the 160 projects were studies, fairs, events and/or trade missions, almost a quarter were on value chain and sector development, around one fifth were on education and capacity development and the remainder were PSI projects. Figure 2 shows that the total budget for the 160 projects was $€ 211,789,211$ and that the largest percentage of this was dedicated to value chain and sector development projects (65\%); followed by education and capacity development (24\%); PSI (7\%); and studies, fairs, events or trade missions (4\%).

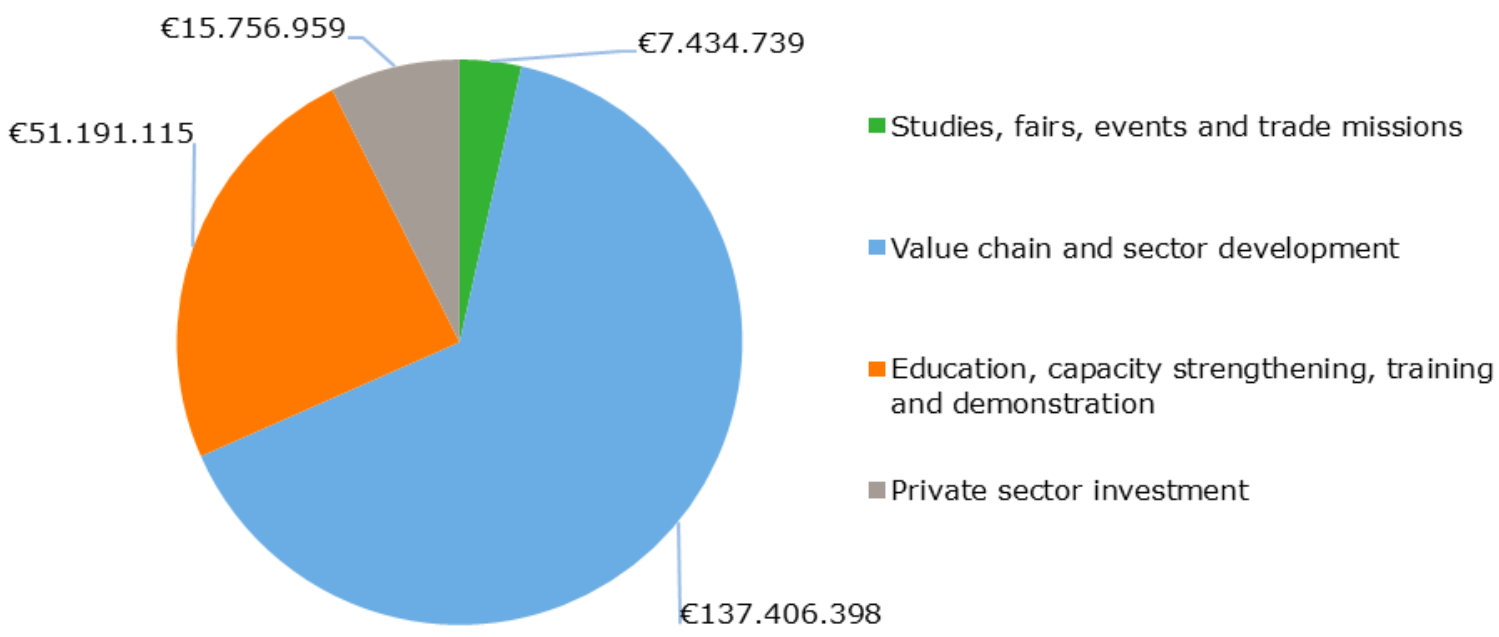

Figure 2 Total budget allocated per project type, in euros 
The division of the budgetary range revealed that the studies, fairs, events or trade missions received the lowest budgets, while the value chain and sector development projects had the highest percentage of larger budgets (see Figure 3).

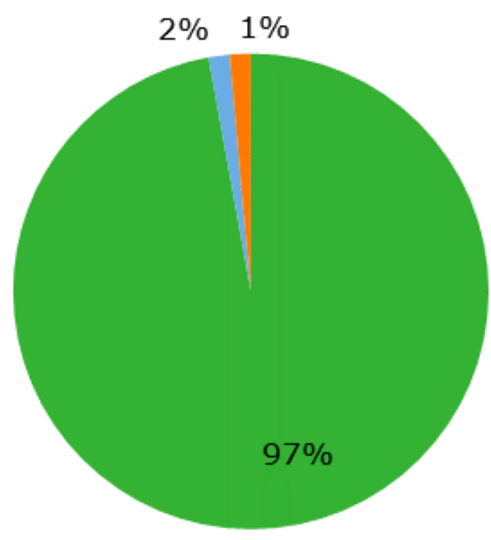

a) Studies, fairs, events and trade missions

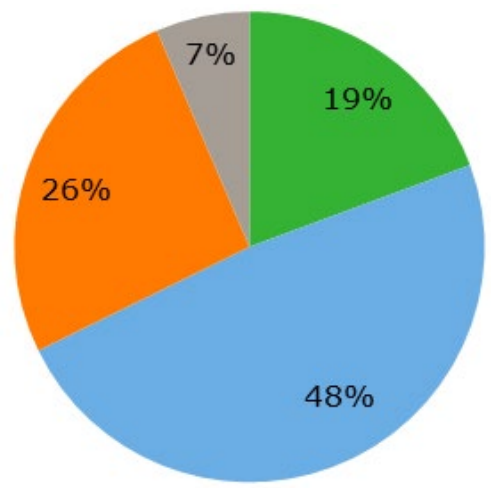

c) Education, capacity strengthening, training and demonstration

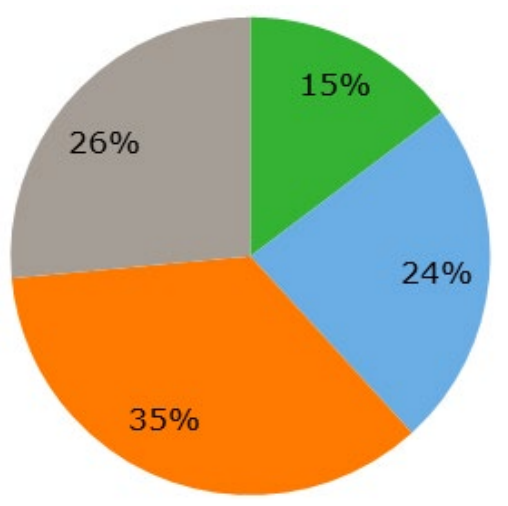

b) Value chain and sector development

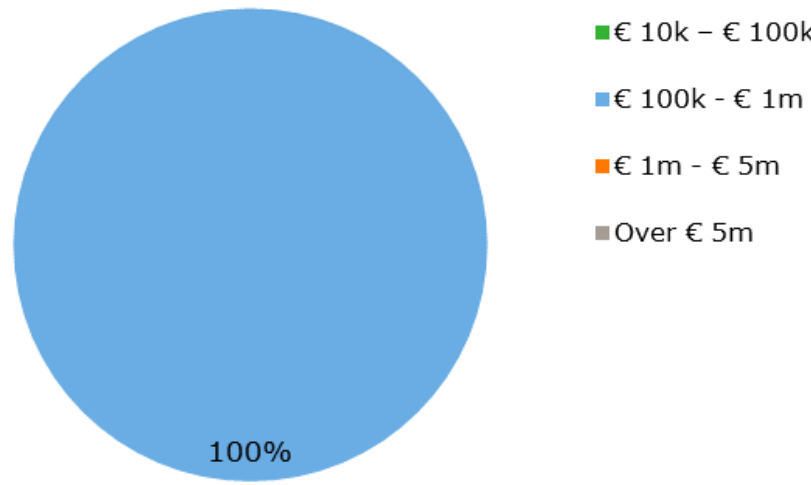

d) Private sector investment

Figure 3 Budget range for a) Studies, fairs, events and trade missions; b) Value chain and sector development projects; c) Education, capacity strengthening, training and demonstrations; and d) Private sector investments

The projects were conducted in 47 countries: 22 in sub-Saharan Africa, 10 in Asia, 7 in the Mediterranean Middle East and North Africa and 8 in Latin America. Five of the projects took place in multiple countries; 1 project had a global approach. The largest amount spent on Dutch-funded horticulture projects was in Ethiopia ( $€ 38,481,537$ or $18 \%$ of the total budget), followed by Kenya ( $€ 25,255,669$ or $12 \%)$, Bangladesh $(€ 16,827,886$ or $8 \%)$, Rwanda $(€ 16,603,634$ or $8 \%)$ and Uganda $(€ 14,904,680$ or $7 \%)$. See Appendix 1 for a breakdown of the amount and type of projects per country. 


\section{$4 \quad$ Key findings and lessons learned}

The adapted components of sector performance (as part of the sector transformation model and defined above in Table 2) were used to structure these general lessons learned. Clustering the outcomes by components helped in grouping the lessons according to their contribution to transformation of the horticulture sector.

Each section in this chapter describes a sector performance component, under which the general lessons learned are formulated and listed. Each component is structured as follows:

1. The component is introduced and an indication given of how much information was available to base the lessons learned on.

2. The lesson learned is formulated and presented in bold.

3. An explanation is given of where this lesson learned stems from, with some background on the project interventions that the lesson learned is based on.

The outcomes of the eight selected projects show that they have all contributed to different components of sector transformation. Some projects are designed to focus on a few components only, while others have a broader scope and, through their interventions, managed to integrate most of the transformation components. Some lessons learned from different projects converge to the same learning point, while others are divergent; for example, key learnings on training interventions that contribute to competitiveness might also contribute to sustainability elements.

\subsection{Competitiveness}

All projects analysed have reported outcomes on the competitiveness of the target groups (small-scale farmers, commercial producers, small and medium enterprises and other value chain actors). Many of these outcomes were related to capacity strengthening, bringing strengthened actors a competitive advantage compared to related peers or businesses or better adjusting production supply to market demand (in terms of quantity and quality). Activities to improve the enabling environment can open up new opportunities for the sector, but can also result in unexpected trade-offs hindering development or limiting competitiveness of innovative and sustainable businesses if other competitors are not required to meet similar regulations or policies.

\section{- Training of trainers approaches have contributed to the scaling up of good agricultural practices, which in turn can lead to higher productivity and better quality products.}

In general, the training of trainers (ToT) approach starts with training and strengthening of specialists such as agronomists who in turn train and provide farmers with improved knowledge and skills, leading to improved farming practices. In general, all the projects demonstrated that capacity strengthening interventions have led to improvements in farmers' productivity and agronomic and economic performance through the adoption of good agricultural practices (GAPs). With simple practices such as raised beds, trellising or the use of specific varieties, farmers were able to increase their productivity, differentiate their production or increase the efficiency of inputs through, for example, reducing the use of pesticides and fertilizers. They gained in competitiveness compared to peers and conventional farming practices and have been able to direct production to better meet market demand. Some farmers were even able to reinvest the additional money earned and bought more advanced farming systems and technologies such as greenhouses or were able to enter highend markets, leading to higher profitability. By practising improved production methods and applying GAPs, producers were also able to increase the quality of their produce, sometimes acquiring certification (as in the GhanaVeg project) or gaining access to new domestic and international market segments, and as a result increasing their sales price. 


\section{- Introducing new service delivery models to the sector without a proper needs assessment}

will influence the level of successful acceptance and adoption of these services.

One example is the use of the Spray Service Providers (SSPs) in the Horti-LIFE project, a specialized service delivery model intended to reduce risks of pesticide use. The SSP concept is developed by the private sector and Ethiopian companies pay a substantial part of the training costs of SSPS. Although designed as a supporting service for farmers, the adoption of the model was challenging because basing a business model for SSPs on one type of service is not sustainable: delivering pest control by itself is not sufficient to sustain the business. Service delivery models like the SSPs should be assessed in their initial stage to link to the needs of the farmers, demonstrate the added value in using these SSPs for pest control and add additional services to the package on offer. Sharing of experiences and learning processes about these models across the various horticulture projects could contribute to improved effectiveness. Currently Horti-LIFE is working with the Ministry of Agriculture to draft a new pesticide regulation that provides space to formalise SSP.

\section{- Support to improve the enabling environment requires the facilitation of public-private collaboration and the management of multiple stakeholder interests; change can bring positive impacts, but also unexpected trade-offs.}

The introduction of the Ghana Green Label (GGL) after the European import ban for selected Ghanaian vegetables is a good example of how a project can contribute to the enabling environment and change in policies and regulations. The accreditation of certified inspectors, conducting regular checks on GAPs and phytosanitary practices reduced the amount of interceptions by the EU from 162 in 2013 to 10 in 2018. This increasing the price that certified producers could set and greatly improved the sustainability of the market by ensuring export. The Horti-LIFE project has worked together with the Ethiopian Ministry of Agriculture to change the pesticide regulation, this is a good example of how combining bottom-up work with strategic support to policy makers leads to results.

However, in the Algerian PSI project, setting too many regulations or unachievable sustainability objectives affected the competitiveness of the actors in the project. Regulations were enforced that allowed only the use of indigenous insects for biocontrol. Other competitors were not required to follow the same regulations, limiting the competitiveness of the supply chains involved in the project. In addition, this was believed to have a negative impact on the potential economic sustainability of the business involved in the project.

\section{- Actively facilitating linkages between producers and actors further along the value chain based on market intelligence has proven to be a good approach for the development of business cases tailored to local contexts.}

Different linkages between producers and other value chains actors were actively facilitated by the several value chain and sector development projects, including linkages regarding markets, knowledge and finance. vegIMPACT used the product-market combination (PMC) to create 10 specific product-market linkages. The idea behind this intervention was to enhance the knowledge both on cultivation and marketing practices to ensure a better connection between smallholder farmers and markets. Training was provided on topics about linking to markets, including how to formulate business propositions, what consumer/retail requirements and quality standards are and how to facilitate contract farming. PMCs were found to be effective in identifying the needs of the market and ensuring that all actors in the supply chain understood and could meet those demands. Sustainability of the PMCs was, however, not always ensured due to other aspects related to contracting issues and lack of transparency and trust, which are elements needed to build a sustainable business relationship.

In GhanaVeg, the establishment of market linkages was supported through a business platform attended by multiple actors, mainly private but also public organizations. The business-to-business follow-up resulted in multiple business deals. In addition, active support was provided, especially to the smaller and newly emerging companies in Ghana to link them to markets. Horti-LIFE successfully linked farmer field schools (FFS) to commercial parties such as agro-dealers; nurseries; traders and micro-finance institutions. 


\subsection{Profitability}

Several projects reported an increase in farmers' income and profitability after they adopted GAPs or benefited from various services offered, initiated or developed during the projects. However, evaluations of profitability gains rely mostly on farmers' surveys and testimonies. For example, in the SEVIA and vegIMPACT projects, farmers stated that they had increased their on-farm income, were able to reinvest this money in their farm or in any other professional activity and/or eventually were also able to improve their own and their families' livelihoods. However, the analysed documents and interviews did not provide direct measured quantitative data to substantiate the increase in income or profitability, and thus remain subjective to some degree. The Horti-LIFE project corrected all data as it was assumed that farmers overestimated the yields of small plots with $25 \%$.

\section{- Introduction of new technologies and high-quality inputs should be accompanied by strengthening of knowledge and skills, to ensure that these resources are used appropriately, farmers and input providers can mutually benefit, and the sustainability of the business case is guaranteed.}

The SEVIA case is a good example of a win-win situation between seed companies and farmers. The in-country breeding programme for both East-West Seed and Rijk Zwaan seed companies was paid for by the companies, while the knowledge transfer activities were financed by the project. The development of locally adapted high-quality seeds was identified as a way to benefit farmers by increasing their productivity. By having the benefits demonstrated to them and being provided with the proper knowledge and skills to make use of the high-quality seeds, farmers are more eager and confident to buy and use these seeds. They understand that the higher costs upfront lead to higher profits. In addition, farmers were supported and taught how to apply GAP throughout the crop cycle. Supporting farmers to access quality inputs so they can grow higher quantities of quality produce, along with investing in capacity strengthening, will financially benefit the entire value chain in the long term.

In one of the Kenyan projects, Growing Solutions Kenya opened the door to year-round production by designing greenhouses compatible with local production conditions and fostering a more efficient way of farming to reduce production costs. It was expected producers would benefit by getting higher prices when market supply is low. Not only would this increase profitability, it would stabilize producer income and increase their market share.

\section{- Co-financing of outgrower models is a good example of how companies and smallholders can mutually benefit from project support.}

In the case of GhanaVeg, through Business Development Funds, several companies established outgrower contracts and sourced horticulture produce from smallholders. They also provided training in GAPs and support to the smallholder farmers. As a result, more than 1,000 farmers obtained a GGL certification for complying with high standards of food safety and judicious use of pesticides and fertilizers. These certification schemes rewarded the smallholder producers for their sustainable production practices with a higher price, while the companies were able to expand and sustainably supply their markets. In this way a market-based incentive was created that encouraged producers to continue to improve quality and sustainability and further develop and expand their businesses.

\subsection{Resilience}

For the horticulture sector, it is particularly difficult to assess and measure resilience in the face of unforeseen or unexpected environmental, economic, social and institutional events. Most horticultural programmes are not primarily aimed at improving the resilience of the sector or its individual actors, although funding institutes are increasingly requesting this aspect be included in project designs. While projects might indirectly contribute to positive changes on this dimension, nothing specific was found in the project reports and documents for the eight projects on the impact of interventions on resilience. 


\section{- Design and implementation of horticulture projects should include a thorough analysis and monitoring of the vulnerability of horticultural systems in order to identify how interventions could positively or negatively contribute to the resilience of the sector and its actors and to select priority areas for improving resilience.}

No clear strategy was observed in any of the eight projects in terms of contributing to resilience of the sector or its actors. This is probably partly to do with resilience being an incomprehensible and complex concept, which makes it difficult to put into practice and monitor, especially as clear indicators and/or outcomes to demonstrate the effects of certain interventions on the level of resilience are difficult to formulate and therefore not really monitored and documented.

\subsection{Innovation and adaptability}

Several interventions were found to have benefited actors in the sector through innovation. Some projects created innovative technical solutions, while others managed to innovate ways to connect sector actors and address challenges by bringing together stakeholders from both the public and private sectors and taking up collective action.

\section{- Facilitating horticulture sector platforms, learning communities and other types of working groups stimulates public-private and sector dialogue to jointly prioritize and address sector opportunities and challenges.}

In Ghana, for example, the established platforms were shown to be effective instruments to, for example, identify costs and benefits of different types of technologies or design a road map on how to address sanitary and phytosanitary issues for the export market. The effect was particularly noticeable at company level, as individual company exports went up and interceptions dropped, helping to reduce economic losses in the horticulture sector. In addition, these platforms facilitated the building of partnerships and creation of business linkages.

Furthermore, the supporting research and development and consultancy funds from the GhanaVeg project helped farmers make informed decisions on, for example, which type of greenhouse to invest in and was used as input for the new financial packages offered through HortiFresh. These supporting studies were also used as background and input during round-table and export task force meetings and informed both private and public actors.

It was also found that supporting learning exchange among actors in the start-up phase can greatly benefit horticultural businesses. Creating an active learning community of entrepreneurs who have been supported or co-funded by the project seems to be a good mechanism to stimulate innovation and collaboration. However, the learning agenda should be derived from a proper needs assessment through which priority learning topics are identified, validated and agreed.

\section{- Putting farmers' needs and local knowledge first when introducing improved technologies contributes to the co-development of solutions tailored to the local context.}

This was particularly visible in the SEVIA case. Extension officers started promoting the use of commercial growing media for seedlings or the use of coconut coir to make home-made growing media. However, it appeared that in some areas neither the commercial growing media nor the coir were available. Through research on the trial farm, SEVIA found that using topsoil, sand and manure - all of which were widely available - in specific ratios also gave a good growing media. This outcome strengthened the relationship between farmers and extension officers, who came up with adapted solutions to farmers' circumstances and conditions.

In Kenya, although greenhouse farming is a familiar and promising technology for local growers, technology uptake had been rather limited in previous projects. Growing Solutions Kenya was able to design greenhouse technology to be compatible with local production conditions, for example by using netting and ventilation systems to control the indoor climate. Designing greenhouses at various price-quality levels and using locally available inputs made greenhouse farming accessible and more financially feasible for small- and medium-sized producers. However uptake of the technology was limited to one demonstration site. 


\section{- Requiring an own contribution, even in the case of resource-poor farmers, effectively}

creates commitment and leads to participatory decision-making.

In the Drops4Crops project in Burkina Faso, members of the cooperative were asked to financially contribute to be able to participate in the development of interventions and benefit from the provided services. Knowing that this project was designed as a business-oriented service delivery organization, and taking into consideration farmers' needs, the programme ensured that participating farmers were empowered to decide on their own situation, supported by various actors. This commitment meant that end beneficiaries were engaged to change their farming systems and follow recommendations from various actors. Trust building and transparency were still required for farmers to be committed to the project and be eager to contribute financially to its development.

\section{- Evidence-based extension models and direct and personal interaction between extension officers and farmers are good ways to disseminate and promote adoption of GAPs.}

Demonstration is a widely used approach to introduce new practices in farmer communities. Its main advantage is that farmers can visually assess the benefits of a given practice. To facilitate this, SEVIA extension officers divided demonstration plots into two subplots where the promoted practices and the farmers' current practices were displayed side by side. The motto used by SEVIA, "Seeing is believing", applied quite literally. Demonstration is a good vehicle for knowledge transfer, giving farmers the choice to decide to adopt the demonstrated practices or not, to facilitate discussion among farmers on the demonstrated practices, and to facilitate trust and transparency in general. Another example is the Growing Solutions project in Kenya whereby demonstrations of three greenhouse models at Latia Resource Centre contributed to the collection and dissemination of data on the efficiency and profitability of production under greenhouses.

Furthermore, the face-to-face extension method is highly valued by the farmers who appreciate a more personal relationship with extension officers. When the officers spent time with the farmers discussing the effects of certain practices, it increased trust and the extent to which the farmers were convinced and willing to try out new practices. This was noticed in various projects such as vegIMPACT, GhanaVeg and SEVIA.

- Working with and supporting innovators, early adopters and lead farmers positively affects the wider adoption of improved farming practices within farming communities, through visual and tangible evidence of the benefits of certain practices and facilitation of peer-to-peer learning.

It was observed that careful identification of and working with "front-runners" can greatly encourage other farmers to adopt new practices. These key farmers are the first to adopt innovative practices within their community. Supported by field officers, these farmers set up demonstration plots on which a comparison between current and innovative practices is displayed. Neighbouring farmers are invited to come and observe these demonstration plots. Sometimes training is also given on these plots. Through discussions with the key farmers and observations of differences between the two subplots results, neighbouring farmers can observe the benefits of GAPs. Peer-to-peer discussions, without the presence of the field officers, allow open exploration of the profitability or practicality of a practice. Discussions might be spread over several seasons as adoption is a lengthy process. External farmers also appreciate the chance to wait and see if the innovator is successful over several seasons within his or her personal field (not on the demonstration plot) before deciding to adopt a new practice. This method has been widely used in the SEVIA and vegIMPACT projects.

- Training sessions should be designed to focus not only on technical content, but also on the learning process so that it is tailor to the targeted learners and context and creates an effective learning environment.

This was an important key learning from the project vegIMPACT, where it was found that although the training sessions were rich content-wise, it was sometimes difficult for farmers to process all the information in a short training session. Farmers also felt that some sessions were too theoretical. The trainers' skills may have played a role, as they focused on transferring knowledge rather than facilitating the learning process. Careful consideration of the content and time/duration of the learning intervention is needed to ensure a good learning experience. 
The Horti-LIFE project has developed a FFS manual on adult education which includes topics on gender and facilitation skills. At the end of the production cycle the learning process at FFS level, at district level and at regional level is reviewed jointly.

The GhanaVeg agronomic ToT programme incorporates a specific module on adult learning and participatory training, to develop trainers' competence in designing, preparing and facilitating agronomic training for farmers. In addition, ideas to improve training included new models for farmer selection, so that training groups were more homogeneous; aligning knowledge to local needs; and investing in dedicated field demonstrations.

\section{- Short training courses can, to a certain extent, contribute to change of some practices, but are often not enough to bring about behavioural change.}

While for some projects relatively cheap and short-term training interventions were found to lead to change in farmers' practices towards GAP, for other projects, intensive training during a full production season seemed to be not enough to guarantee adoption and behavioural change. In the case of vegIMPACT, both the one-season farmer field school approach and a three-day training session during one growing season were effective strategies that improved intermediate outcomes. vegIMPACT highlights that short interventions and dedicated pitches of extension messages in practical environments may result in improved knowledge transfer and awareness.

On the other hand, in various projects, including SEVIA as well vegIMPACT, it was suggested that providing continued access to extension officer support for more than one season would improve farmers' confidence in adopting improved practices. In GhanaVeg, the private agronomists of the participating companies were included in the ToT to guarantee long-term sustainability. This implies that a key condition for success is the sufficient and continued availability of public but also increasingly private extension workers.

\subsection{Sustainability}

Several horticultural projects worked on the environmental dimension of sustainability, but few worked holistically to address all three aspects by including the economic and social dimensions.

Horticultural projects focus largely on the adoption of sustainable practices either at the farm gate or at the business level. The adoption of GAPs should lead to more efficient use of pesticides or improved fertilization practices, limiting the impacts of farming activities on the environment. While some projects were able to demonstrate that better handling and use of pesticides has led to positive outcomes, there was little documentation on the extent of which these projects contributed to other areas of sustainability, such as better working conditions, worker's rights and gender equality.

\section{- Providing specific training on integrated pest management (IPM) and GAPs effectively reduces reliance on pesticides and increases the adoption of sustainable farming practices.}

In the GhanaVeg project, agronomists were capacitated through a ToT and in their turn taught producers how to implement IPM and GAPs, which helped them reduce pesticide use during production and residue levels in the final product. As a result, 1,000 farmers obtained GGL certification for complying with high standards of food safety and judicious use of pesticides and fertilizers. Many smallholder farmers were also trained through the Business Development Funds, through which companies established outgrower contracts.

In the case of vegIMPACT, knowledge transfer reached more than 10,000 farmers. Farmers felt that the project contribution to adoption of IPM and GAPs greatly influenced reduced use of pesticides. vegImpact also dedicated a specific work package to occupational health, with the aim of reducing the health risks to farmers, labourers and their surrounding community of occupational pesticide exposure risks, with specific attention to women. They organized training activities, dialogues, 
workshops and awareness campaigns. Part of the approach included training on safe and responsible use of pesticides.

The Horti-LIFE project also helped reduce the use of hazardous pesticides with higher toxicity and supported many producers to adopt IPM. Promoting more complex IPM methods requires more time, and limiting the use of harmful pesticides requires long-term support for all stakeholders in the pesticide supply chain.

\section{- A valuable contribution to sustainable water use in horticultural production appears to be possible even with relatively simple solutions and small investments.}

In the case of GhanaVeg, for example, through support to develop greenhouse production and acquire irrigation systems, producers decreased their susceptibility to water shortages and harsh climatic conditions. Additionally, this enabled farmers to move towards year-round production of vegetables and reduced their susceptibility to market price fluctuations and irregularity of income.

In the vegIMPACT programme, by implementing simple methods such as placing a plastic sheet in a dug hole, farmers were able to store water to extend their production period and meet crop water needs. Better access to water enabled farmers to grow and harvest for a longer period, which helped them to reduce their vulnerability to income fluctuation.

In the Drops4Crops project, digging water points and developing Integrated Water Use Management Plans has brought access to water in drier periods to a large number of vegetable growers. Alongside the introduction of improved farming practices, this was beneficial for farmers, helping them to properly manage their resources for the long term.

\subsection{Exit strategy}

Project-initiated activities aim to create tangible outcomes during the project; however, they are also expected to sustain impact after a project ends. Exit strategies, when planned before project closure, ensure better project outcomes and encourage commitment to project sustainability.

Although within the eight horticulture projects various elements could be identified that relate to lasting project impact, it seemed that the exit strategies of the various projects are not always clearly defined and remain rather indistinct. Some of these elements of sustainable impact are listed below and are mostly related to embedding the project in local institutions or enterprises.

\section{- Ensuring the impacts of project-supported or -initiated activities are sustained after the project ends requires the activities to be embedded in local institutions or enterprises.}

In the case of Horti-LIFE, farmer field school (FFS) models were very successful in reducing pesticide use. The continuity of the FFS would have been at stake if no attention would have been paid to institutionalizing the extension model, still work in progress, and the necessary resources to keep the FFS running after the project ended were no longer available (e.g. budget, sufficient capacity for skilled and trained extension officers). Combining direct support to farmers and development agents with support to policy development at regional and federal level was the key to in institutionalizing FFS and formalizing SSP.

In the GhanaVeg programme, funds for business opportunity and research and development gave some companies the chance to develop innovative initiatives while receiving additional business development support, increasing the sustainability of both the innovative capacity and the business model of the beneficiary companies. R\&D funds supported companies to develop and register new vegetables varieties, as well as introducing new crop protection and irrigation practices. Business opportunity funds enabled 43 businesses to adopt innovations and invest in new technologies. These funds allow companies to develop and test, over several years, innovations, technologies and service models, while receiving business development support then enables them to improve the potential sustainability of the activity after the project ends. 


\subsection{Inclusiveness}

Although most of the projects included women, youth and marginalized groups in their interventions, limited information was available on this component. Some reports did not explicitly indicate how they addressed gender inequalities or managed to include youth or vulnerable people in their approaches. Some projects indicate the number of women and youth reached, but no clear learnings in this area were reported.

Most of the projects involved smallholders, but there was limited description about the types of farmers and lack of information about what worked well to involve smallholders or resource-poor farmers.

Despite the lack of information on this component, some key learnings from the more gendersensitive projects could be formulated.

\section{- Training designed to consider women's needs and time availability improves the engagement and interest of women in capacity-strengthening activities.}

Engaging women in training activities was found to be challenging at times, because the activities were not always adequately designed to consider women's needs and time availability. In the HortiLIFE project, activities were undertaken to sensitise field staff on the specific needs of women, and to train women in leadership, public speaking and technical aspects of farming. Women were not very motivated to join technical training as it took too much of their time, and sometimes women preferred to rent out their land instead of working the land themselves.

GhanaVeg surpassed each of their inclusivity targets, for women, youth as well as smallholder farmers involved in their activities. As shown in the SEVIA project, the age of farmers also influences the adoption rate of new technologies, as young farmers are more attracted to them.

\section{- Offering capacity-building and GAP training activities to workers and contractors, who have important roles in the horticulture sector, and not only on farmers, could bring additional positive impacts.}

Experiences from vegIMPACT show that contractors and (female) field workers are frequently hired for specific field activities (planting, weeding, harvesting, pesticide spraying) in which they are most vulnerable to potential occupational health risks. Projects often overlook these agricultural workers, perpetuating the systemic issues such as health risks. vegIMPACT addressed this issue by organizing training, activities, dialogues, workshops and awareness campaigns aimed at reducing the health risks to farmers, labourers and their surrounding community of occupational pesticide exposure, with specific attention to women.

\subsection{Transparency}

The ability to deliver open, relevant information and data to its actors is key to a well-performing horticulture sector. From the analysed projects, it was found that improving the flow of information and transparency among the sector players was not really a core part of the design of the projects. However, some projects did implement activities that brought relevant information to the sector or supported improved transparency.

\section{- Building trust among sector actors is essential to better link smallholder farmers and markets.}

Project interventions must go beyond a focus on strengthening capacity to produce and meet GAPs. Negotiation skills and knowledge about market dynamics are also key factors to success. In the case of vegIMPACT, for example, the product-market combinations (PMC) were found to be a suitable approach to inclusiveness because the actors were involved in selecting the appropriate PMC and business proposition. However, there were also other market dynamics factors influencing the success of a particular business case. In this case, competition between actors was found to be a challenge and influenced the sustainability of business relationships and thus success of the PMCs. 


\section{- Sharing market information and farm performance data can benefit the sector and increase transparent trade.}

In the Drops4Crops programme, transparency is considered necessary to build trust between farmers and the other actors. Structuring the cooperation as business-oriented service delivery (credit, land tenure, extension) and defining in detail what farmers can expect from the project has created trust and fosters project development. In addition, returning information related to the outcomes of the project interventions allow an honest dialogue between actors to be maintained. When farmers see the benefits, they are more eager to invest in GAPs and in the project itself, despite living in a vulnerable area or conditions, therefore contributing to better profitability of their activity.

A similar dissemination of the outcomes of demonstrations was undertaken in the SEVIA, vegIMPACT and Growing Solutions Kenya projects. For example, in the Kenyan project, Latia Resource Centre collected data on the application of water, fertilizers, and crop protection products, as well as tomato harvests and sales. The collected data was used to calculate production costs, revenues, gross margins, return on investments and the payback period for each of the greenhouse models. Sharing data on farm performance with producers and investors was intended to stimulate trust in the profitability of the promoted practices or technologies as well as in the messages of extension officers or companies and increase demand for new technologies and adoption of improved production practices.

\section{- Establishing collaborations with other actors in the sector to close knowledge gaps effectively generates valuable information for producers.}

Access to information remains a major bottleneck for farmers. In the SEVIA project, the extension field officers who provide agronomic advice to farmers did not have any expertise on vegetable markets and economics. Other actors such as the Tanzanian Horticulture Association (TAHA) generate relevant knowledge and information, especially on market prices and commodities stock. However, they do not have an extensive field team to disseminate this information. With the collaboration between SEVIA and TAHA, field officers were able to create a flow of information across Tanzania by establishing a network of other actors in the vegetable sector.

In the vegIMPACT project, the knowledge dissemination strategies between private input supply companies and extension services had multiple benefits. The same was true of the knowledge transfer between institutes and private sector networks, which made it possible for knowledge to reach farmers so they could get valuable insights about improving their systems. 


\section{$5 \quad$ Discussion and conclusions}

This paper sought to collect the key findings and formulate general lessons learned from horticulture sector programmes, projects and collaborations in LMICs funded by the government of the Netherlands, through the Ministry of Foreign Affairs and the Netherlands Enterprise Agency (RVO), through a quick analysis of a selection of eight representative horticultural projects.

The analysis of the eight horticulture projects serves as background and input for future Valuable Vegetables learning activities, supporting its overall objective: To learn from ongoing and completed programmes in the horticulture sector and to communicate the lessons learned with the wider food and nutrition security network, in order to both improve and innovate in approaches, practices and policies and to contribute to food and nutrition security. This descriptive and analytical exercise aimed to give insights into the outcomes and impact areas where horticulture project interventions have contributed to sector transformation. The analysis found a variety of activities and interventions that do contribute, to a greater or lesser extent, to elements of sector transformation.

The majority of the lessons learned from the eight analysed projects were in the areas of competitiveness and innovation and adaptability, and related more specifically to capacity strengthening and facilitating linkages within the horticulture value chain. Undoubtedly, there are many more lessons that can be drawn from these eight projects; however, these have not emerged within the limited scope of this quick scan, partly due to the fact that the more detailed lessons cannot be extracted directly from the project documentation. One of the challenges in how projects report is that the food and nutrition security framework of the Dutch Ministry of Foreign Affairs ${ }^{5}$ focuses on indicators relating to reach and targets as numbers, hectares and percentages. There is little space for more reflective learning and examination of system changes in this framework. It is therefore advisable to organize further discussions and exchanges in which project leaders, project staff and related stakeholders bring out possible deeper lessons, either with the project team or between different projects and programmes. The latter is expected to be taken on by the Valuable Vegetables learning initiative.

Key learnings in the competitiveness component showed that the ToT approach has led to broad adoption of GAPs and that investing in capacity strengthening of farmers' production practices can lead to improved production systems, increased income and a more competitive position overall within the market. Furthermore, other approaches were found to be effective. These included the use of platforms to jointly prioritize and address sector opportunities and challenges, to build sustained partnerships and to create business linkages; the use of evidence-based extension as a mechanism to disseminate GAPs; and context-specific design of capacity development activities.

On the training modalities, it was found that more practical designs were needed to go beyond content and to consider the skills that trainers should possess to guarantee more effective learning experiences for farmers. The learnings show that although short training sessions can, to a certain extent, contribute to change of some practices, often they are not enough to bring about behavioural change. Fostering successful approaches such as peer-to-peer learning could increase the motivation for farmers to join an initiative or adopt new practices. Thus, it is recommended to design projects using, for example, demonstration plots and to combine that with an active role for lead farmers with skills in motivating their peers on the learnings. In addition, involvement of qualified public or private extension officers with sufficient financial means as well as back-up support could possibly increase the outreach and sustainable impact and widely benefit the sector as a whole.

Regarding the sustainability component, a clear focus on the environmental dimension of sustainability was observed. The main learnings included the success of promoting IPM to reduce the use of

5 See: https://www.dutchdevelopmentresults.nl/theme/food 
pesticides, and the interventions to contribute to sustainable water management. Since information and the reporting on this component was limited, it might be worth examining the extent to which these and other projects have addressed systemic sustainability issues other than the environmental dimension. It would also be desirable to focus on issues hampering the social sustainability of the horticulture sector such as income and/or employment for smallholder farmers, youth and women; a living income; violation of worker's rights; and occupational conditions.

The lack of documented evidence to sustain the contribution to resilience and inclusiveness suggests that projects have not included the related indicators to be reported on, or they are not explicit about the way they address these elements, or they might not necessarily have been able to focus on these issues in the way that was foreseen, which brings limited insights to share and learn from. As both resilience and inclusiveness are becoming increasingly important themes, and are more and more expected to be integrated into horticulture sector programmes, it might be valuable to explore how projects could be more explicit about their strategies to contribute to resilience and inclusiveness. This is even more important in light of the recent COVID-19 pandemic (which happened during the finalization of this study) and the measures taken to restrict the spreading of the coronavirus worldwide, which has had and will continue to have significant consequences and challenges for the horticulture sector across all countries, both in the short and long term. This experience of such an unexpected and disturbing event is currently accelerating reflection on resilience and the general capacity of the sector to absorb economic, social, environmental and institutional shocks and stresses.

It is also of value for future projects to build on learnings about the potential of outgrower schemes as a way to include smallholders and to bring positive impact to their livelihoods. Critical questions should be posed around the matching grants funding instruments that are frequently applied in horticulture sector programmes: whether they have the desired impacts on smallholders and do not just further strengthen the market position of commercially oriented companies, and whether these are the most efficient tools to deploy resources to reach desired impact according to the value for money principles of economy, efficiency and effectiveness.

One key learning in the transparency component was the need to build trust among sector actors. Although horticulture projects have brought more than just technical expertise to the sector by working on topics like entrepreneurship, market development and financial literacy, there is also value in building trust among actors, creating better systems for data sharing and ensuring that information generated from the projects reaches farmers so they can benefit from it. Another area for future research is how to incentivize farmers to associate so they can get more bargaining power and possibilities for partnering in projects, rather than being just the beneficiaries of development cooperation capital.

The study of the exit strategy elements in the projects found that those projects that included multistakeholder partnerships to co-develop innovative solutions and business cases contributed to the scaling up of initiatives after project interventions, especially when the context of the sector was carefully taken into the design. The inclusion of a variety of actors, all integrated into the value chains and at different scales, makes it possible to provide tailored solutions and generate smart information for the improvement of the sector. The inclusion of public actors seems to have both positive and negative aspects: getting local authorities to support projects can create a conducive enabling environment with regards to trust and institutional alignment, but at the same time can cause substantial implementation delays due to bureaucratic issues. In addition, the exit strategies of projects are not always clearly defined and remain rather indistinct. Future projects are advised to develop more detailed and solid exit strategies well in advance of project closure, to ensure better project outcomes, encourage commitment to project sustainability and sustain impact after a project ends.

Finally, we can conclude that to better understand the learning points within any horticulture project, a deeper look at the outcomes of the project and more in-depth discussions are required with a variety of actors, not only the project leaders or project staff. Furthermore, more follow-up activities are necessary to better understand the outcomes and impacts of a project on the horticulture sector in the respective country and its contribution to sector development or transformation. But more 
importantly, learnings from ongoing and completed projects in the horticulture sector could greatly inform improvement and innovation in the approaches, practices and policies of future initiatives. Currently such lessons learned are not yet sufficiently shared among the project implementing organizations. The objective of the Valuable Vegetables initiative is to change this by facilitating learning and sharing with the wider food and nutrition security network; to offer key players in the horticulture sector a platform to share, learn and exchange knowledge and experiences; and to develop, implement and scale innovative solutions for challenges in the sector. The aim is to improve and innovate in approaches, practices and policies to contribute in the end to food and nutrition security.

\section{Next steps}

The Valuable Vegetable initiative, led by the F\&BKP, will organize a series of learning events, in which outcomes can be challenged, further explored and analyzed. The insights from this paper will serve as the agenda. Based on the findings and outcomes described here, the following themes are suggested for the future Valuable Vegetables exchange and learning activities:

- Resilience: How can strategies be improved to enhance the contribution of projects to resilience in the horticulture sector?

- Inclusiveness: How can strategies be improved to enhance the contribution of projects to inclusiveness in the horticulture sector?

- Sustainability: How can strategies be improved to enhance the contribution of projects to environmental, social, economic sustainability in the horticulture sector?

- Review of current horticultural extension and capacity strengthening models: How can the impact of agricultural extension and capacity strengthening methods and approaches be sustainably improved in the horticulture sector?

- Systems change: What systemic approaches can be taken towards horticulture sector development / sector transformation? How can systemic bottlenecks be addressed?

- Matching grants funding instruments: Do matching grants have the desired effect and impact on the ultimate target groups? Are matching grants the most efficient instruments to get the desired impact according to the value for money principles of economy, efficiency and effectiveness?

- Effective exit strategies: How can a short-term project incorporate an effective exit strategy? How can multiple actors - both public and private - engage in this at an early stage of project development? 


\section{References}

Adger, W. N., Brown, K., Nelson, D. R., Berkes, F., Eakin, H., Folke, C., ... Tompkins, E. L. (2011). Resilience implications of policy responses to climate change. Wiley Interdisciplinary Reviews: Climate Change, 2(5), 757-766. https://doi.org/10.1002/wcc.133

Dijkxhoorn, Y., Galen, M. van, Barungi, J., Okiira, J., Gema, J., Janssen, V. (2019). The vegetables and fruit sector in Uganda: Competitiveness, investment and trade options. Wageningen, Wageningen Economic Research, Report 2019-117

IFAD. (2009). Sustainability of rural development projects. Best practices and lessons learned by IFAD in Asia. Occasional Papers - Knowledge for development effectiveness \#8. http://www.videa.ca/wp-content/uploads/2015/07/Income-generating-crafts.pdf

Ministry of Foreign Trade and Development Cooperation. (2018). Investing in Global Prospects. https://www.government.nl/documents/policy-notes/2018/05/18/investing-in-global-prospects

Ministry of Foreign Affairs. (2020). Programme budget chapter XVII Foreign trade and development cooperation 2020. Government of the Netherlands.

https://public.tableau.com/profile/ministerie.van.buitenlandse.zaken\#!/vizhome/RijksbegrotingHo ofdstukXVII/ChapterXVII.

Molenaar, J. W., Gorter, J., Heilbron, L., Simons, L., Vorley, B., Blackmore, E., Dallinger, J. (2015). Sustainable sector transformation: How to drive sustainability. performance in smallholderdominated agricultural sectors? White Paper 1. Commissioned by IFC. https://pubs.iied.org/16584IIED/

Molenaar, J.W., Vorley, B., Blackmore, E. (2017), Reaching beyond the value chain; How sector governance can improve the performance of agricultural commodity sectors, Aidenvironment, IIED and Sustainable Food Lab

RVO (2020). RVO project database. https://projects.rvo.nl/section/development-cooperation/

van Gent, S. (2017). Beyond buzzwords: What is "inclusive development"? INCLUDE. Synthesis report. https://includeplatform.net/wp-content/uploads/2017/09/Beyond-buzzwords.pdf 


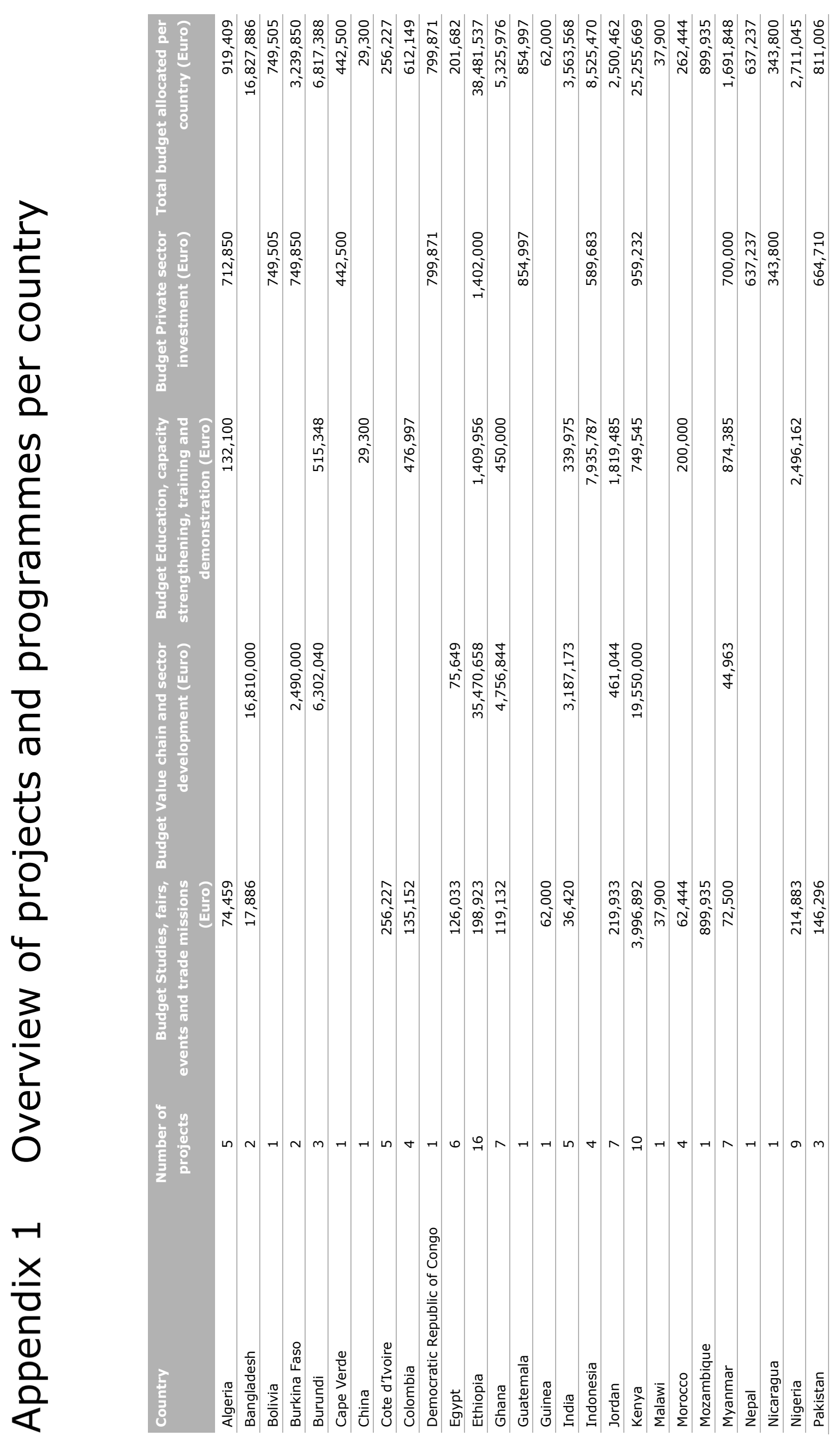




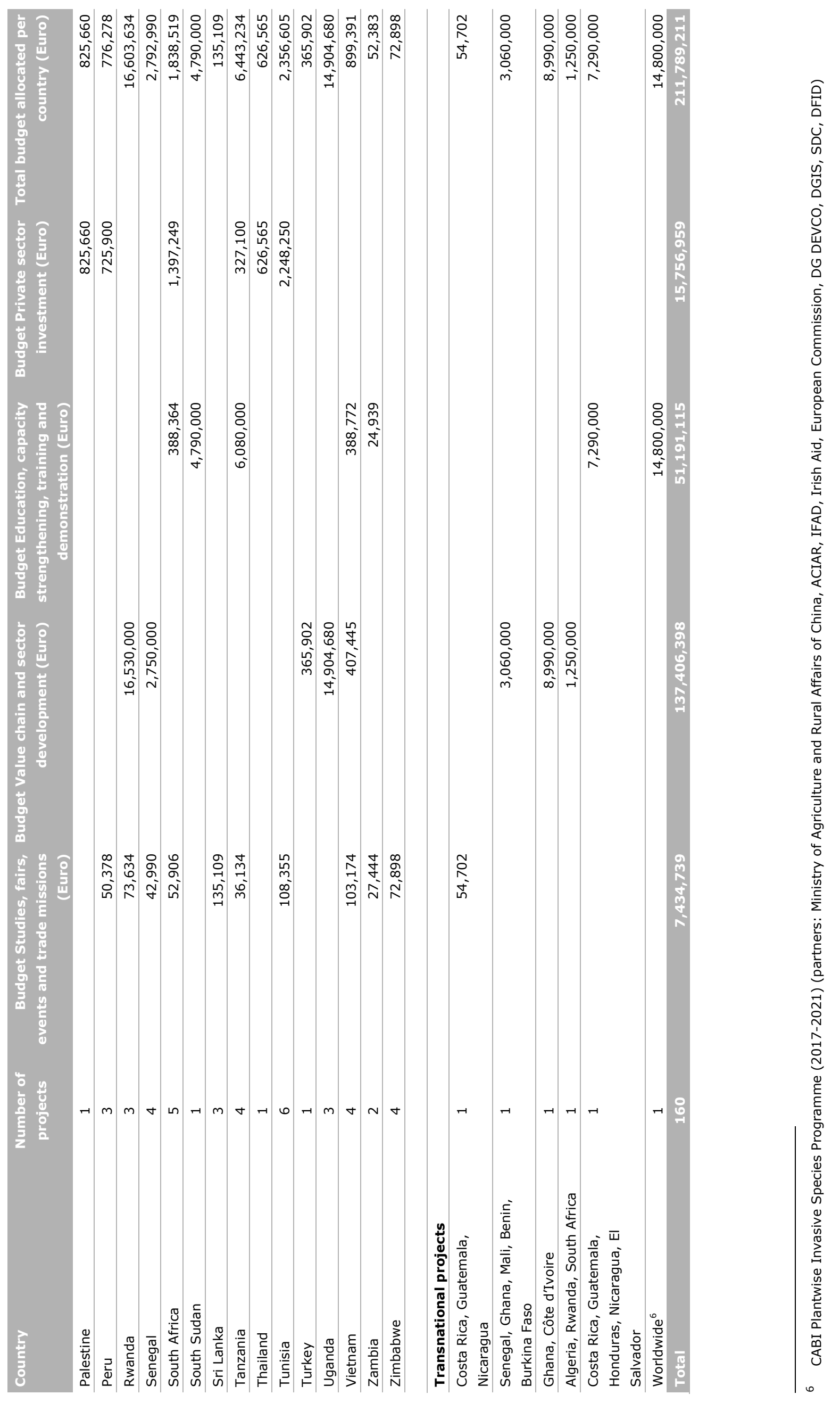




\section{Appendix 2 Analysis of selected projects}

In this appendix the summaries of the analysis of the eight selected representative horticultural projects are provided. These summaries have been compiled by the study team based on personal communications with the respective project leaders and through analysing the project documentations shared with or retrieved by the study team. The final summary reports have been reviewed and validated by the respective project leaders of the eight selected horticultural projects.

\section{Horti-LIFE}

Text provided by Mr. Gerrit Holtland, Horti-LIFE, SNV

Horti-LIFE (Horticultural Livelihoods, Innovation and Food safety in Ethiopia) is a program funded by the Embassy of the Kingdom of the Netherlands (EKN) and implemented by SNV in cooperation with the Ministry of Agriculture. The first phase ran from January 2016 till mid-2019 with a budget of 7 million Euro. The second phase runs until mid-2023 with a budget of 20 million. The project operates in 30 districts (48 as of Sept. 2020) in the four main regions of Ethiopia: Tigray, Amhara, Oromia and SNNPS.

The overall aim of the program is to increase rural incomes, jobs and diet diversity by improving the productivity, diversity and food safety in the horticultural sector. It works in five main areas i) Productivity and diversity ii) private service provision to smallholders iii) food safety iv) practical education in horticulture iv) nutrition.

The core of the program are Farmers Field Schools (FFS) working on Learning and Linking. FFSs are a group of 30 smallholders learning together on Good Agricultural Practices and IPM. The FFS is also a way to informally link its members to service providers.

Horti-LIFE supports both the learning and the linking. The next graph shows the different project interventions that are all geared to creating well-functioning Farmers Field Schools that will lead to the desired outcomes of higher productivity and affordable safe fruits and vegetables.

The overall approach of Horti-LIFE

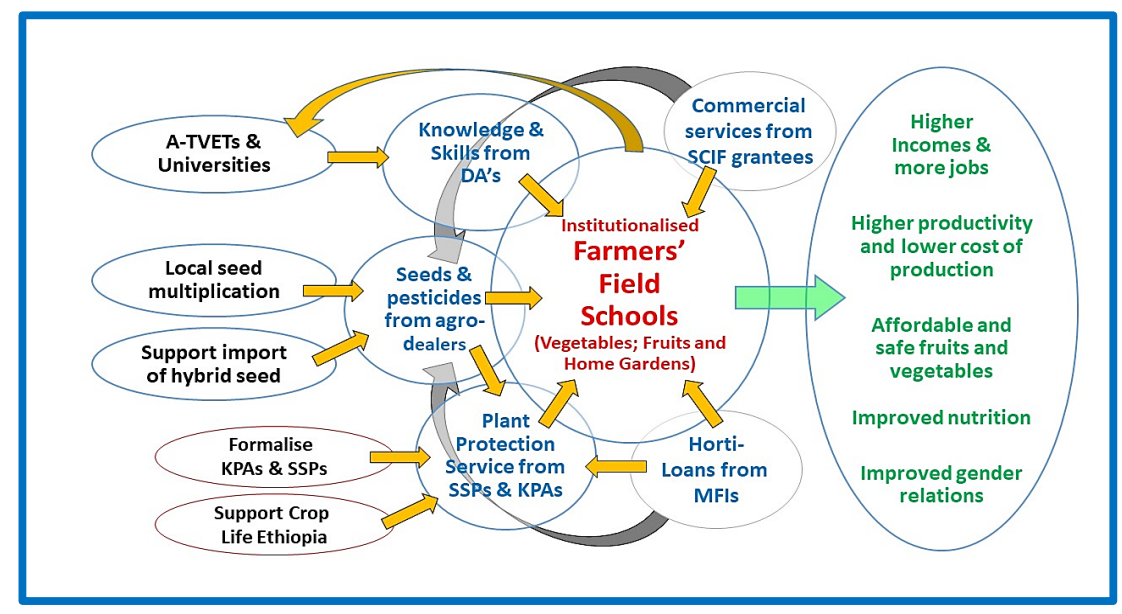

Horti-LIFE supports the FFSs, as well as five service providers to the FFSs:

1. Development Agents (DA's) who establish and facilitate the learning process in FFSs are trained and coached. Also the inputs for FFSs come via them. The Woreda Agricultural Office where the 
DA's are employed are also capacitated. As a second layer of support educational institutes are capacitated to improve the practical skills of future DA's.

2. Spray Service Providers (SSPs) who offer spray services to FFS members are trained and provided with PPEs. Per village one Kebele Pesticide Agent (KPA) is trained to offer plant protection advice. $\mathrm{He}$ is linked to an agro-dealer. As a second layer the Plant Health Regulatory Directorate (PHRD) was supported to formalise the position of SSPs and KPAs.

3. Commercial firms offering services to FFS members (agro-dealers; nurseries; marketers). They can benefit from a SCIF grant and are linked to the FFS via Cluster Workshops on Input Supply in Horticulture (C-WISH).

4. Agro-dealers \& seed multipliers are supported so that they can offer quality seeds to smallholders. This refers to improving the local seed production of onion \& potatoes and to facilitating the import of hybrid seeds.

5. MFIs are supporters to offer horticultural loans to smallholders, agro-dealers, KPAs of SSPs.

The learning in FFS is based on four learning plots owned and managed by elected (rotating) lead farmers. During the production cycle FFS members meet every 3-4 weeks on these plots to observe and discuss the four P's: Plot (erosion; wind breaks; hygiene etc.), Plants (vigour; colour, fruit setting, etc.), Pests (scouting; thresholds; control measures etc.) and Practices (weeding, staking, irrigation frequency etc.).

The extension messages consist of a package of 18-20 innovations based on production technologies used on commercial farms. The main innovations are: hybrid seeds, seedbed preparation \& seedlings, improved pest scouting and better pesticides selection \& application, IPM (e.g. wind breaks), improved fertilisation (e.g. use of potassium) and GAP (e.g. staking). Commercial farms are not only the sources of the innovations but also of all key project experts. So they have hands-on experience with the technologies.

The FFSs are established by the extension workers of the MoA (they are called Development Agents or DAs). In the first season (2016-17) 108 FFSs were established in 9 woreda's (districts). In the second season this increased to 133 FFSs in 13 woreda's. In the third season three other projects started to co-finance the FFSs and the number jumped to 324 FFS in 27 woreda's. In the present season (2019-20) one regional government started to co-finance as well and the numbers increased to 384 FFS in 30 woreda's. So far some 3,500 farmers have been lead farmer and over 20,000 farmers have been member. Well over 50,000 participated in field days.

Positive results have been observed with the FFS. Out of the 1,075 FFS members (30\% women) who participated in an adoption survey in $2019,88 \%$ said they learned to identify new pests. The costs of pesticides per $\mathrm{kg}$ of produce are $43 \%$ lower on learning plots, but higher per hectare. The higher costs is a combination of a halving of the number of spraying rounds while the pesticides that are used are more expensive (more specific and less harmful).

The data of nearly 500 FFSs give the following outcomes:

- Investments per ha increase by $60 \%$ (40\% for short term crops; $80 \%$ for long term crops).

- Yields ${ }^{7}$ are double the yields of lead farmers' fields (which on their turn are twice the average yields of all farmers in the area).

- Net incomes jumps with 6.900 USD/ha or $166 \%$ (from 4.200 to $11.100 \mathrm{USD} / \mathrm{ha}$ ).

- The cost price per $\mathrm{kg}$ is $24 \%$ lowers (it ranges from $20-30 \%$ over the seasons and crops).

- Fertiliser use on short term crops is $25 \%$ more efficient; for long terms crop it is the same ${ }^{8}$.

- The costs of pesticide per $\mathrm{kg}$ of produce is down by $43 \%$ (see above).

- The Return on Investments are good at all levels. It is over $100 \%$ for traditional fields and nearly $200 \%$ for learning plots. This gives a RoI of over $300 \%$ for the additional investments.

7 As the learning plots are small (200 sq. m.) and the farmers might be inclined to exaggerate the difference between the learning plot and the regular farmers' fields we assume that they yields of the learning plots as reported by the FFS are $25 \%$ higher than the real one. The numbers mentioned here are based on the corrected data.

8 This is logical as the availability of nutrients from the soil decreases as the cropping season progresses. So for long term crops an increasing share of the nutrients has to come from the fertiliser (hence a lower yield per qt of fertiliser). 
The learning is far from complete; the focus in many FFSs is still on pest control via pesticides with limited attention for a wide range of IPM measures. However this is slowly improving as more attention is given to pest scouting and thresholds, to intercropping, to irrigation practices etc. The limited range of active ingredients on the market is a challenge. A large survey on the pesticide supply chain showed serious problems at all levels: registration of new pesticides, imports of cheap generics, illegal imports, limited capacity of agro-dealers, lack of skills etc.

Due to the impact of the FFS in the country, the state minister asked the project to support MoA in designing a new horticultural extension system in which the FFSs could be embedded. Three rounds of consultations with regional BoAs and national level stakeholders lead to a number of key-challenges:

- lack of budget and of any decentralised planning system for extension activities;

- inadequate task description and limited skills of Development Agents (DAs);

- lack of knowledge and skills to design extension messages at higher levels.

Regarding the adoption of hybrid seeds, the average area for which smallholders buy hybrid seeds is 0.3 ha. So after the first 3 seasons hybrids were planted on over 500 ha. With an additional profit of 4.000 USD/ha this represents an additional smallholders' income of 2 million USD. More detailed calculation lead to a RoI for all project investment in FFSs of $19 \%$.

the program results show that farmers are eager to adopt such innovations. However, there are some challenges related to the access to hybrids seeds. The imports of hybrid is hampered by a limited access to forex. Horti-LIFE worked to address by working together with the government to facilitate the imports.

Horti LIFE has stablished nearly 100 students plots to enhance the knowledge on vegetable production for students of the TVETs. The FFS approach is used in those plots to teach students of the TVETs who will be working as extension officers after graduation. The idea behind is to make their education more practical.

Furthermore, Horti-LIFE worked with the Spraying Service Providers approach (SSPs) which was developed by Crop Life International. A SSP is a farmer trained in pesticide application, who offers spray services to his peers against payment. Horti-LIFE asked FFS members to select one farmer to be trained and become SSP. However, there were challenges in the adoption. The reasons are diverse: some trained farmers were not willing to offer services; some were seen by their peers as insufficient competent (especially on pest scouting); some farmers already paid a full-time worker for all field work, including spraying; some farmers felt the project should pay the SSPs; or that the SSPs should offer services for free as they have benefitted from the training and some felt the government should decide on the price for the services. Furthermore, it was noticed that SSPs were not sufficiently business and service oriented, and more training, community dialogue and promotion is needed.

As the SSPs were only offering physical spray services, the project developed a new concept: Kebele Pesticide Agents (KPA). They are better off farmers who are trained to advice farmers on pest scouting, IPM and pesticide selection. They are connected to an agro-dealer in nearby district town who provides them with small amounts of pesticides in consignment. They sell these for a small commission. The KPA concept is still being explored. The project works with the Plant Health Regulatory Directorate of MoA to formalise the position of KPAs and SSPs through a new Directory that include these two in the regulatory setting. On the training component, KPAs and SSPs have received training on technical issues provided by staff of pesticide companies that are member of Crop Life Ethiopia (CLE). These trainings are given for free. The companies see their contribution to the training as part of their corporate social responsibility (stewardship in Crop Life terminology) and as part of the business interest to build up a network of trained KPAs and SSPs in horticultural areas.

In 2019 Horti-LIFE started to supports Crop Life Ethiopia to set up a business unit that can train, coach and monitor KPAs and SSPs. A manager has been employed to run this unit. The principle clients for the unit are development projects; next to Horti-LIFE this refers to a USAID and a GIZ project to date. One element in the capacity building of Crop Life Ethiopia (CLE) is the design of a business model on how to charge projects for the costs of training, coaching and follow up and how 
these revenues can be distributed between CLE, the trainer and the company where the trainers works. A second element is the establishment of a database with all SSPs and KPAs to monitor their services and incomes. This can be used to further refine their business models, the prices for services and how to promote them.

\section{Lessons learned}

Competitiveness and profitability

- Horticultural FFSs are a very effective learning method that leads to very high Returns on Project Investments.

- Innovation packages based on the practices of commercial farms are very successful under smallholder conditions; especially when the experts introducing this package have hands-on experience with it themselves.

- The fertiliser recommendation originating from the research system need to be updated based on the availability and quick adoption of hybrid seeds by smallholders. Tailor made advice per crop and agroecology are needed.

- The combination of hybrid seeds and FFS lead to a quick adoption of these seeds and to substantial improvements in the productivity and profit of smallholders.

Innovation and adaptability

- Combining direct project support to FFSs with support to services suppliers of FFSs was successful. It lead to important synergies between FFSs and SSPs but also between FFS and SCIF grantees, seed multipliers (not explained here) and A-TVETs.

Sustainability

- FFS are very useful in introducing IPM among smallholders. An initial focus on reducing the use of oldfashioned pesticides and on proper application methods is effective.

- Limiting the use of harmful pesticides also requires long term support to all stakeholders at different levels in the pesticide supply chain.

- Promoting more complex IPM methods requires more time and huge capacity building efforts at all levels.

- KPAs \& SSPs are useful to inject more skills on pesticides and pesticide application in the farming community. Yet more has to be done on IPM training, formalising the positions, business development and creating a sustainable (private) support system.

Exit strategy

- Institutionalising FFSs is a long term process as decision makers are frequently changed and there is no budget (nor a planning system) for any extension activity. Despite this two (of the four) regions adopted the FFS approach and now plan how to support them.

- Working with A-TVETs is good way of improving the technical and facilitation skills of the (future) extension workers.

- Combining direct support to farmers and DA's with support to policy development at regional and federal level was the key to the success in institutionalising FFSs and formalising KPAs and SSPs. Thousands of learning plots showing very good yields created to a bottom up change process led by farmers, extension workers and district level staff. 


\section{Smart Adaptive Sustainable Horticulture in Rwanda (SMASH/SMART)}

The SMART project was initially planned for South Africa (high-tech), Algeria (medium-tech) and Rwanda (low-tech). However, because of the interests of local commercial parties, it was only implemented in South Africa (high and medium-tech) and Rwanda (low-tech).

This project description focuses on Rwanda where greenhouse technologies have been introduced and adopted for the production of high-value crops like tomatoes and sweet pepper. However, since the introduction of plastic greenhouse technologies, there was limited adoption to high tech technologies (which was an initial focus of the project) due to the lack of skills to operate and maintain the high tech technologies.

Smart Adaptive Sustainable Horticulture in Rwanda and South Africa was launched in 2012. The aim of this project was to enable farmers to develop a sustainable and profitable business in which productivity and food-safety could be addressed. The project aimed to overcome the difficulties farmers had encountered earlier when high tech solutions were offered to them, by offering various levels of technology in different settings.

SMART was a public-private partnership that introduced system innovation through technology in the horticulture sector. The SMART project focused on providing technology in combination with training and taking the local environment and expertise into consideration. Holland Horti International, Wageningen University \& Research, BoP, TNO, Rijk Zwaan, Koppert, Bosman van Zaal, Hoogendoorn and Holland Greentech Ltd (HGT) were the main Dutch partners for the implementation of the project, collaborating with Rwanda Best a medium sized Rwandese enterprise.

The training to other farmers covered a) open field cultivation, b) tunnel and shade net houses, basic greenhouses and c) multispans. SMART managed to develop the planned 3 pilots. In Rwanda, SMART reached about 5.000 farmers.

The approach used for the project included:

- Selecting lead farmers (Rwanda Best in Rwanda, Klein Karoo in South Africa)

- Designing pilot greenhouses adapted to the local environment

- Supply chain analyses, identifying market opportunities

- Training lead farmers

- Training other farmers - organizing farmer field days

In total, 16 commercial farms were trained during the SMART project. Basic, medium and high technology greenhouse pilots were set up in South Africa and Rwanda. Different types of technological solutions for large, medium and small companies were disseminated.

Results of the different technological levels included:

1. Development of demonstration plots together with lead farmers in the different Rwandan Districts (30)

2. ToT training package for farmers to start and support farmer study groups

3. Organization of Farmer Field Days (FFD) with on average 40 farmers

4. Support on soil analyses, pest control, irrigation technology, improved seeds and shade nethouses and good farming practices

5. Training at demonstration farms in implementing cultivation concepts and mechanization: training in soil cultivation (to improve soil structure and soil oxygen availability)

6. Tailor-made advice on soil analysis using simplified test results from SoilCare

7. Provision of hybrid varieties, quality seeds

8. Advise on pest control products to reduce the use of pesticides.

SMART project contributed to the development of competitive production models. Real business cases of systems with various technology levels were tested and adapted to the local conditions. The project 
developed an interesting approach which enabled farmers to transition from basic technology implementation to a more advanced adoption of technology. This ensured a gradual transition, which resulted to be effective for farmers to establish their businesses and get the necessary

training/knowledge for the adoption. Although the interest in high technology greenhouses was raised, only a few greenhouses were sold. According to the results of the project, the main reason for nonpurchase was political uncertainty.

Innovation targeted to the local context was part of the approach used by SMART project. Different types of technological solutions were developed for large, medium and small companies. The pilot greenhouses combined different innovations both applicable and affordable for Rwandan growers. Examples of innovation include the development of greenhouses with rooftop ventilation, the use of substrate and the use of biological pest control.

The project also contributed, through the companies involved in the start of the project, to the development of a service delivery model which included: a package of suppliers for soil analysis, fertilizers, vegetable seeds, crop protection, irrigation, shade net and green houses. This model is replicated in other countries.

\section{Lessons learned}

Competitiveness

- Trainings are needed to guide farmers when introducing a next technological level in horticulture.

- It is crucial for a farmer to choose a technology level that suits with their expertise.

- Each step to a new technological level requires new expertise, farmers cannot jump from level 1 to 5 .

- Besides the knowledge on greenhouse technology, it was found that more training was needed at demonstration farms to reduce post-harvest losses. In addition, further support for building cool storage is necessary to maintain good quality.

Innovation and adaptability

- To introduce next levels in greenhouse technology, partnerships were important as to guarantee proper support to farmers in adopting those technologies. 


\section{VegIMPACT}

Wageningen University \& Research, Fresh Dynamics Asia and the Indonesian Vegetable Research Institute (IVEGRI) implemented the vegIMPACT programme from 2012 to 2017 in collaboration with Indonesian and Dutch private sector companies. PT East West Seed Indonesia (EWINDO) / Panah Merah through its non-profit Corporate Social Responsibility Foundation Yayasan Bina Tani Sehjatera (YBTS) was the most important collaborating company.

One of the intervention strategies in this programme was focused on the development of pilots implemented with partners in the value chain, where smallholder farmers produce according to the specific market demands. The so called Product Marketing Combination (PMC). In total, 10 product marketing combinations were developed involving 163 farmers and 8 companies.

The idea behind this intervention was to enhance the knowledge on cultivation and marketing practices to ensure a better connection between smallholder farmers and markets. Some of the technologies supported with this intervention included the use of new varieties to improve yield and quality. Many of the interventions focused on practical training and capacity building of farmers and other stakeholders in vegetable chains.

Other interventions in the programme focused on permanent vegetable systems, potatoes, knowledge transfer (KT), and occupational health. Various interventions used demonstration plots to engage with stakeholders and to show benefits of new technologies and cultivation practices.

The approach used to identify the needs of the different regions reflects an effort to target the real needs on the ground. Focus groups with the actors were established to analyse what those PMCs should be to match the actors' needs. The activities included the development of training materials, designing and setting up field demonstrations for training purposes, training of trainers and training smallholder farmers, overall supervision and, if needed, mediation among actors in the value chain.

The results indicate that large-scale rollouts of training activities on farming practices and market access have the potential to lead to improved production, productivity and quality of vegetables. Knowledge was transferred via the training of trainers (ToT) and training of farmers (ToF) model. VegIMPACT and IVEGRI experts trained 137 Field staff (product promotors) of EWINDO, who on their turn trained thousands of farmers across Indonesia.

Knowledge Transfer reached more than 10,000 farmers, and with this intervention there were other interesting results including the distribution of 1269 booklets, 609 pesticide safety brochures, 1346 leaftlets and 790 Edugames on occupational health. Furthermore, PPE equipment was delivered with the project for occupational health (720 masks) and e-learning modules on crop protection, spraying techniques, fertilisation and nursery management. In addition, a free app was developed with state of the art knowledge on horticulture. More than 11,000 downloads were recorded during the evaluation of the project.

Farmers perceived that the programme contribution to adoption of IPM and GAPs in general had a great influence in the reduction of pesticides. Furthermore, trainings were extended to topics important for the supply chain, including the formulation of a business proposition, the training on consumer/retail requirements (including quality standards) and facilitation in contract farming.

The programme showed significant contributions to the promotion of viable and sustainable vegetable cropping systems. Over the entire programme period, more than 15,000 farmers across Indonesia were reached with trainings, field expos and workshops. In addition, vegIMPACT produced leaflets, short films, posters, slides and other communication material, both in print and by digital platforms on the website and in the MyAgri app, in close collaboration with Balitsa. VegIMPACT also reached 850 stakeholders in dissemination workshops around the PMC concept and lessons learned from the 10 pilots across Indonesia. This shows efforts to stimulate sector dialogue. Furthermore, within the different work packages, the programme stimulated the collaboration with the private sector, for example, with the Dutch company De Groot and Slot and Si Technology for the testing of shallot varieties and improving soil fertility, respectively, in Indonesia. Furthermore, within the work package Occupational Health, contacts with Croplife-Indonesia were established, in order to analyse the 
establishment of a joint pesticide container recycling system. Although the latter could not be executed without proper environmental permits.

Although VegIMPACT contributed to the sector with the different interventions, there were some challenges linking smallholder farmers and traders though the PMCs, which emerged from their relations and lack of trust. Those challenges included the violation of contracts and price agreements, the mismatch of demand and supply due to the difficulties to produce during wet seasons (higher pest outbreaks) and the outstanding debts and high market prices of new seed varieties. Few of the established farmer-trader relationships was found to be functional mainly due to the lack of trust between farmers and traders limiting the achievement of a transparent, fair and sustainable trade.

\section{Lessons learned}

Competitiveness

- More training on organizational performance, marketing and market access is needed to be able to build trust between traders and farmers.

- More practical approaches to training are desirable and less theory, at the same time pedagogical skills of the trainers can be enhanced.

- Public-private collaboration in providing extension services has multiple and mutual benefits for both private companies and knowledge institutions.

Resilience

- Understanding local diversity in vegetable production systems is important. It contributes to harness the potential of the horticulture sector and addresses the needs of the sector.

- Horticulture potentials and needs for development depend on local biophysical conditions and associated cropping systems, markets, political-institutional setting and socio-cultural situation.

- The horticulture sector and its particularities regarding diversity in cropping systems, seasonality and variation in weather conditions makes it difficult for projects to get accurate insights in the attribution of impact and M\&E data collection.

Innovation and adaptability

- Experiences from vegIMPACT show that relatively cheap and short-term training interventions can already change the behaviour of farmers towards GAP. In the case of vegIMPACT, both one-season farmer-field school approach (10 daily sessions per season) and a three-day training during one growing season were effective strategies which resulted in improvement of intermediate outcomes. However, trainings can be improved. Farmers found that the trainings contained too much information dealt with in a short period of time.

Inclusiveness

- Experiences from VegIMPACT show that contractors and field workers are frequently hired for specific field activities in which they are most vulnerable to potential occupational health risks or other issues.

Transparency

- Building trust among value chain actors is essential in order to increase transparent trading. 


\section{GhanaVeg}

Launched as a private sector-led sector development programme, GhanaVeg (2013-2017) aimed to establish "a sustainable and internationally competitive vegetable sector that contributes to inclusive economic growth and has the capacity to continuously innovate in terms of products and services". Activities were designed to stimulate a competitive high-value vegetable sector driven by innovation and endorsing sustainable production methods; a conducive and enabling policy environment; and inclusive economic growth. GhanaVeg's Final Report was used to analyse its contribution to the 9 Sector Performance Components presented in Aidenvironment's diagnostic tool.

GhanaVeg's contribution to production took many forms, including activities aimed at increasing productivity, profitability, exports, share of domestic market, as well as embracement of sustainable production methods. Such activities included agronomy trainings, supporting certification for good agricultural practices, and providing Business Opportunity Funds. A total of 60 agronomists completed an intense year-long Training of Trainers (TOT) with theoretical and practical field sessions, each of which trained at least another 50 farmers. Twenty-five percent of the farmers trained through the ToT and other Ghana Green Label (GGL) agronomy trainings saw at least 50 percent increase in productivity. Following these trainings, 1,000 farmers became GlobalGAP or GGL certified, which increased their access to new market segments, valuing sustainable production methods and encouraging producers to continue improving quality and sustainability.

Service oriented activities, such as organizing agronomy trainings and improving access to inputs, technology and certification, were designed to meet the stakeholder needs and improve the quality of vegetable production. Other service oriented activities included communication activities, publishing illustrative guides for crop production and providing various funds. For example, the Consultancy and R\&D Innovation Funds were used to analyse business opportunities and competitiveness within the vegetable sector. They were also used to study, test and report potential benefits of new innovations and technology under local farmer conditions.

GhanaVeg's support for capacity building in terms of track-and-tracing, certification, cooling, storage, and packaging to maintain quality of export products contributed to value chain development in the fruit and vegetable sector. GhanaVeg also supported mutually beneficial outgrower contracts, which guarantee SMEs input supply while smallholder farmers are guaranteed a market to sell their produce. Through these contracts, SMEs also supported smallholder farmers with agronomic specialists, tractors, irrigation and other inputs. Farmers and SMEs alike benefit from the improved productivity and quality of produce. A total of 71 dedicated chains were developed as a result of GhanaVeg activities, 27 of which in the form of outgrower schemes.

When an export ban was placed on chillies, eggplants and gourds (Ghana's main export crops), GhanaVeg played a vital role in establishing an Export Taskforce, responsible for resolving the export ban, implementing remedial actions, and ensuring effective monitoring of phytosanitary issues. Through the Export Taskforce, Roundtable meetings and Business Platforms, GhanaVeg contributed to improved dialogue and coordination to increase awareness and use of good agricultural practices. This was complemented by demonstration trials on 10 export farms, where integrated pest management practices were exhibited. GhanaVeg also contributed to knowledge development and distribution through their R\&D Innovation and Consultancy activities. These covered topics such as access to finance and greenhouse technology, which were also discussed during Roundtable meetings and Business Platforms.

GhanaVeg also contributed significantly to the regulation of the vegetable sector, particularly where phytosanitary issues are concerned. A consultant was hired to conduct an analysis of the Sanitary and Phytosanitary Status (SPS), which informed GhanaVeg's further discussions and activities, such as Export Taskforce activities, Roundtable meetings and Business Platforms. Through these activities, GhanaVeg worked closely with the public and private sector in an effort to improve quality of vegetables, remove the export ban, and prevent further EU interceptions. When the programme started in 2013, there were an average of $162 \mathrm{EU}$ interceptions per year due to SPS issues in exported vegetables. By 2017, 5 policy or regulatory changes were effectuated due to GhanaVeg activities. 
These included establishing an Export Taskforce, endorsing the GGL strategic plan, and developing a pesticide residue monitoring plan. This resulted in a clear protocol for reducing pest populations, which the EU accepted when they lifted the export ban late 2017. Between January and May 2018, only 10 interceptions were reported, which can in part be attributed to GhanaVeg's activities to improve regulation.

GhanaVeg invested in Ghana's vegetable sector in many ways, including its various funds. The 11 R\&D Funds were awarded primarily to companies developing and registering new vegetable varieties, as well as introducing new crop protection and irrigation practices. Similarly, the Business Opportunities Funds and training enabled 43 businesses to adopt innovations or invest in new technologies, such as solar irrigation. Furthermore, by organizing trade missions and connecting the Dutch private sector to local stakeholders, 14 Dutch companies invested in i.e. fresh and organic vegetable production, seeds, organic herbs, consultancy, cooling systems, and machinery between 2013-2017.

In terms of contributing to landscape, GhanaVeg activities reduced the impact of vegetable production activities on the environment and human health. This was done through intense training on good agricultural practices. As a result, 1000 farmers obtained certification for complying with high standards of food safety and judicious use of pesticides and fertilizers. These certification schemes, including Ghana Green Label and GlobalGAP, combine food safety, environmental protection and profit, serving as market-based incentives for better production practices.

Inclusive growth was a cross-cutting theme in GhanaVeg's activities, more specifically aimed at involving women, youth, and smallholder farmers in project activities. In this regard, GhanaVeg surpassed each of their inclusivity targets, with 1,564 women, 1,999 youth, and 6,843 smallholder farmers involved in their activities. These women, youth and smallholder farmers were involved in activities such as agronomy trainings, contract farming, and the Business Opportunities Fund. Out of the 3,867 trained farmers, for example, 66 percent were male, 34 percent female, and 47 percent youth younger than the age of 25 . As such, GhanaVeg contributed to improved welfare within communities, through improved income generating opportunities and training.

When GhanaVeg ended in 2017, the programme was extended until 2021, now operating under the Commercial Fruit and Vegetable Sector Development in West Africa (HortiFresh) programme. Building upon GhanaVeg and lessons learned, HortiFresh has extended its activities to Côte d'Ivoire and now includes the fruit sector. 


\section{Lessons learned}

Competitiveness

- There needs to be better dialogue with the public system to address systemic issues particularly in regards to phytosanitary services, food safety and environmental sustainability, and increased effectiveness when working closely with the private sector.

- Further study needs to take place on the increased effectiveness of projects like the Ghanaveg, when working with larger companies with a proven track record, willing to invest in smallholder farming.

- We need to intensify comprehensive training modules for farmers and strengthen linkages between suppliers and off-takers.

- Working with Dutch companies willing to combine trading products with agronomic services and aftersales support is an advantage.

Resilience

- In regards to strengthening capacities of current and future horticulture entrepreneurs, GhanaVeg activities on good agricultural practices (i.e. Training of Trainers for agronomists, who went on to train outgrowers, some of whom ended up Ghana Green Label certified) were most impactful. These trainings led to behavioural and structural changes in farm management and improved the quality of produce.

- Supporting producers in the move towards year-round production contributed to a reduced susceptibility to market fluctuations.

\section{Exit strategy}

- The Business Opportunities Fund was the most notable activity when it comes to creation and sustainability of horticulture businesses and investments. These co-financed funds gave companies several years to develop innovative initiatives, while receiving additional business development support, increasing the sustainability of impact at company level. One particular example is that of Eden Tree Ltd., a vegetable producer and distributor, which was initially too small-scale to obtain a bank loan.

\section{Inclusiveness}

- One of the key lessons learned was the need to develop training modules covering a wider range of activities and ensure stronger linkages between suppliers and off-takers (Broek et al. 2018).

\section{Transparency}

- The export ban placed by the Ghanaian government was particularly influential in transforming the horticulture sector. While the short-term economic impact on the sector was particularly negative, it did increase awareness among actors on the consequences of phytosanitary issues and thus, the necessity to improve farm management and increase professionalism across the sector. This transformation was largely facilitated and reinforced by the Export Taskforce. This multi-stakeholder effort was successful in raising awareness, facilitating change, reducing phytosanitary issues, and removing the export ban.

- The R\&D and consultancy funds were essential for increasing knowledge within the sector, particularly studies done by the University of Ghana on how to best manage and quarantine pests in the field, as well as the design of a road map on how to produce safely for export. The effect was particularly noticeable at company-level, as individual company exports went up and interceptions dropped. A study on the costs and benefits of different types of greenhouses, for example, exemplifies the role of the R\&D fund in stimulating innovation within the sector. The study guides farmers in deciding which type of greenhouse to invest in and is used as input for the new financial packages offered through the project. These studies were used as input during Roundtable and Export Taskforce meetings, informative for both private and public actors. 


\section{Growing Solutions Kenya}

Implemented between 2013-2016 by a consortium of 12 Dutch greenhouse technology providers, Growing Solutions Kenya (GSK) aimed to contribute to improved position and living conditions amongst small- and medium-sized vegetable producers through greenhouse farming. Working through the Dutch private sector and focusing on production for the local market, greenhouse technology was adapted to local conditions and made available for small- and medium-sized tomato and capsicum producers, guiding them from a low-tech to a tailor-made mid-tech production facility. GSK's final report was used to define its contribution to sector performance.

GSK's contribution to sector performance was primarily through its focus on production activities, particularly economic viability, land use efficiency, climate resilience, and environmental sustainability. More specifically, greenhouse models were designed and adapted to local production conditions, such that they could increase the quantity and quality of output, as well as lower inputs and costs per unit of output, thus increasing efficiency. Successful ventures could increase farm profitability, enabling producers to not only earn a living wage and repay their loans, but to also reinvest profits to continue developing their greenhouse activities. GSK's greenhouses were also designed to be more resilient to light intensity, weather conditions, climate change, pests, and diseases, through ventilation systems and netting. This controlled internal climate allows producers to produce year-round, benefitting from higher, out of season prices, a stable income, and a larger share of the market. Capacity building, irrigation systems, or even fertilizer units allow for more efficient and effective use of inputs (i.e. water, fertilizers, crop protection products), reducing the impact of production activities on the environment and increasing food safety for consumers.

Through capacity building activities, collecting and sharing data with the general public, as well as increasing accessibility of greenhouse technology to those with varying degrees of financial means, the programme was also very service oriented. By designing three different types of greenhouses, with different materials, designs and levels of investment, GSK made its products and services accessible to different types of producers. The three types included the Basic Greenhouse, Plus Greenhouse and the Advanced Greenhouse, each differing in materials and systems used, but still adapted to local conditions and using available inputs. Offering these three types of greenhouses increases the target group reached, allowing small scale producers to start small and gradually intensify and increase production. It provides small scale producers with future perspectives and an incentive to continue developing their greenhouse. Each of these greenhouse models was tested and demonstrated at Latia Resource Centre, where 270 people visited the greenhouses, excluding those participating in GSK's capacity building activities.

Capacity building activities took various forms, including a demonstration plot at Latia Resource Centre in Kajiado county, field days (approx. 300 participants), study groups (77 participants), technical training, financial training (24 trainees), and a Train-the-Trainers programme (15 participants). Each of these, as well as the seminars, covered a wide range of topics. Topics included greenhouse systems and climate control, quality standards, biological control, business planning, financial management, as well as requirements and conditions for loans and certifications. Those working at Latia Resource Centre expressed that, through GSK and the Train-the-Trainers programme in particular, they acquired access to knowledge previously unavailable in Kenya. Not only did they indicate that their knowledge on high wire, greenhouse vegetable production was significantly higher, but they are confident enough to train and provide business support to others. GSK also received positive feedback from producers who applied learnings with successful results. Unfortunately, by the time the GSK project ended, additional yield, income, investments and employment could not be quantified, because only one production cycle had been completed. However, delegations from other African countries (i.e. Tanzania, Uganda, Rwanda and Ethiopia) were inspired by GSK activities and eager to look for or establish similar programmes in their country. The Rwandan government, for example, had already asked Latia Resource Centre for advice on how to develop a similar training centre and greenhouse in Rwanda.

GSK was not very active in terms of sector coordination activities, with the exception of knowledge development and sharing. Latia Resource Centre collected data throughout the implementation of the 
three greenhouse model demonstrations. This included data on the application water, fertilizers, crop protection products, as well as data on tomato harvests and sales. The data was used to calculate production costs, revenues, gross margins, rate of return on investments, and the payback period. As can be seen in the table below, the results of the first production cycle were positive, with all three greenhouse models proving profitable under local conditions. These calculations were later presented to the wider public, including financiers, input suppliers, and the local government. This was particularly used as a proof of concept for producers and investors, to show profitability and success of the greenhouse models. As such, GSK shared their knowledge and experiences with greenhouse technology.

Investment overview Growing Solutions Kenya

\begin{tabular}{|c|c|c|c|c|c|c|c|}
\hline \multicolumn{8}{|c|}{ INVESTMENT OVERVIEW GROWING SOLUTIONS KENYA } \\
\hline Parameter & Unit & 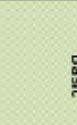 & 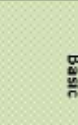 & ${ }_{n}^{\frac{D}{L}}$ & $\frac{\text { D }}{\bar{L}}$ & 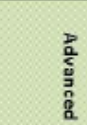 & 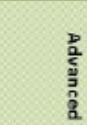 \\
\hline Surface & $m^{2}$ & 1500 & 5000 & 1500 & 5000 & 1500 & 5000 \\
\hline Total Investment & $1000 \mathrm{KES}$ & 9.320 & 18.975 & 11.920 & 22.750 & 15.405 & 29.650 \\
\hline Investment per $\mathrm{m}^{2}$ & KES & 6.213 & 3.795 & 7.946 & 4.550 & 10.270 & 5.930 \\
\hline Total Investment & $1000 \mathrm{E}$ & 84,7 & 172,5 & 108,4 & 206,8 & 140,0 & 269,5 \\
\hline Investment per $\mathrm{m}^{2}$ & $\epsilon$ & 56,5 & 34,5 & 72,2 & 41,4 & 93,4 & 53,9 \\
\hline No of workers & & 4 & 10 & 5 & 12 & 6 & 14 \\
\hline Yield per $\mathrm{m}^{2}$ & $\mathrm{~kg}$ & 22 & 22 & 28 & 28 & 40 & 40 \\
\hline Average Price per $\mathrm{kg}$ & KES & 70 & 70 & 70 & 70 & 70 & 70 \\
\hline Forecasted revenue $/ \mathrm{m}^{2}$ & KES & 1.540 & 1.540 & 1.960 & 1.960 & 2.800 & 2.800 \\
\hline Forecasted sosts $/ \mathrm{m}^{2}$ & KES & 1.162 & 868 & 1.438 & 1.033 & 2.036 & 1.466 \\
\hline Forecasted profit $/ \mathrm{m}^{2}$ & KES & 378 & 672 & 522 & 927 & 764 & 1.334 \\
\hline IRR & $\%$ & 3,3 & 20,3 & 3,9 & 22,9 & 5,0 & 23,8 \\
\hline Payback Period & Years & 8,2 & 4,1 & 8 & 3,8 & 7,8 & 3,6 \\
\hline
\end{tabular}

Source: Groot (2017). Growing Solutions Kenya Final report. Delphy BV.

The programme's contribution to sector landscapes mostly took the form of designing and providing greenhouses that manage water, sunlight exposure, and phytosanitary risks, through i.e. netting and airflow. Mitigating these natural disturbances ensures productivity and viability of the production unit.

Support to communities was mostly indirect. GSK aimed to increase living standards and well-being, although this would be an indirect result of successful greenhouse farming. Unfortunately, the data available at the time of writing the report was only of the demonstration plot, as no local producers were using the GSK's greenhouse technology at the time. Furthermore, Latia Resource Centre hired 5 people as a result of GSK activities. However, there is a potential for more employment if demand for these greenhouse models increases. Local SME investors would need trained and experienced grow managers who can manage greenhouse activities and guarantee return on investments.

After four years, GSK and their activities at the Latia Resource Centre were declared successful, leaving a strong foundation, positive image and growing interest in greenhouse technology and inputs, which other companies can benefit from. It was, however, not without challenges. Lessons learned include:

- The demand for greenhouse technology for vegetable production is there, in Kenya and neighbouring countries, but complementing Dutch greenhouse technology with capacity building and business support services is essential for successful sales and impact.

- The 1-year implementation period was too short. Another 2 years would have allowed for a greater impact in terms of evidence-based promotion of greenhouse technology, local capacity building, and stronger spin-off effects. Furthermore, the time needed for preparatory activities should not be underestimated.

- Designing greenhouses that meet local production conditions, complement what is already available on the local market, consider accessibility of inputs, finance, markets and capacity building, as well 
as reflect the technology and interests of the private actors is very time consuming. It took at least one year for GSK to design greenhouses that take each of these factors into consideration.

Attention for building local capacity and experience in high wire, greenhouse vegetable production should be a priority. Another challenge is reducing the risk of trained and experienced staff leaving for other opportunities.

\section{Lessons learned}

Competitiveness

- In regards to strengthening capacities of current and future horticulture entrepreneurs, the Study Groups and the Training-of-Trainers programme were particularly valuable. All Study Group participants were farmers from the region, most of whom already had experience with greenhouse based production. With gatherings spread throughout the implementation phase, sessions could cover different phases of the production cycle, combining theory, GSK greenhouse visits and practical assignments. The Training-of-Trainers was particularly valuable, because participants expressed a high level of confidence so that they could train others, in turn strengthening the capacities of a growing number of horticulture entrepreneurs.

- GSK interventions were not directed at improving the enabling environment, except by making Dutch greenhouse technologies available to and functional for Kenyan producers. Similarly, they worked together with local seedling suppliers, for example, to ensure that necessary inputs could be sourced locally. Unfortunately, the options and quality were limited, reducing the output.

\section{Exit strategy}

- GSK interventions and investments did not directly foster creation and sustainability of horticulture businesses. However, the production and investment data collected on GSK's 3 greenhouse models served as a proof of concept to producers and investors interested in greenhouse vegetable production. In this sense, GSK maybe have inspired and contributed to new initiatives after the programme ended. GSK's activities have also formed a strong foundation, on which Dutch and local businesses can build.

Others

- Though exact figures are not available, collection and distribution of data on GSK's 3 greenhouse models is expected to have contributed Kenya's horticultural sector development. At the time, producers and investors showed an increasing interest in greenhouse technology and inputs, requesting information on production potential and results, investment costs, training, support, and local availability of the technology.

- Data on the effects of GSK activities on food and nutrition security, gender and climate resilience was not available in the Final Report, thus no measurable effect can be noted. 


\section{Empower high-end vegetable supply chain by young plant production in Algeria}

The project called Empower high-end vegetable supply chain by young plant production in Algeria is a PSI project which started in 2013 and will end in October 2020. Subsidized by the Ministry of Foreign Affairs of the Kingdom of the Netherlands, PSI projects follow a similar scheme: together with a local company, a foreign company creates a venture to answer a certain need identified in a country. These needs can be diverse: agriculture, infrastructure, etc. The maximum budget allocated to such programmes cannot exceed $€ 1.5 \mathrm{M}$. Although diverse in their sector, PSI projects aim at "buying impact". This can be translated by an important emphasis put on job creation through the development of a new business and knowledge transfer from the applicant (Dutch or not) to the local company. The transfer of knowledge is done at all levels in the new venture, from management to field work, in order to sustain the business when the project comes to an end.

Empower high-end vegetable supply chain by young plant production in Algeria stemmed from the observation that farmers in Algeria were facing a shortage of good quality seedlings in certain periods of the year and that they, unfortunately, tried to import such materials from neighbouring countries. In addition, seedling raising methods in Algeria are still traditional, leading to poor young plant material and loss of money. Therefore, working with high-quality and hybrid seeds in Algeria was considered as not worth it. By combining the building of a proper nursery site, combined with extensive knowledge on seedling raising from the Netherlands and high-quality seeds, substantial results were expected both in terms of seedling production and profitability. They planned on building modern greenhouses to grow disease-free and high-quality seedlings, grafted or non-grafted, which will be then sold to farmers who in turn can benefit from a good starting material to grow vegetables. The identified vegetables for which a seedling market has been identified were mainly peppers, cucumbers, tomatoes and eggplants.

The project gathers 4 partners. Firstly, GrowGroup International BV is a large Dutch horticultural company. Secondly, the local partner Global Santé is a trade company that (through its owner) is participating in Primagri, a seed company in a joint venture with Cotugrain Hortimag, the third partner. The latter is a company supplying horticultural raw materials from and in Tunisia and also owns a joint nursery in Tunisia with Pépinière Grow Tunisia who is the last partner in the venture. All together, they submitted a proposal to create the first professional plant nursery in Algeria. GrowGroup International BV would be responsible of bringing and sharing their knowledge and expertise on seedling production to the local partners, who would be in charge to "run the business", including after the end of the project ${ }^{9}$

Most of the PSI projects are aiming at four main outcomes:

1. Administrative: to obtain permits and authorization to set up a new joint venture

2. Building the production site

3. Hiring and training new people

4. Getting the business running and profitable.

The first stages of the project were a bit delayed as it took time to set-up the business. In addition, towards the end of 2019, the local partner decided to bail out of the project. Although it is possible to change partners during the PSI project, finding a new one appeared to be a difficult step. Just recently, a new partner has been found to pursue with all activities until the end of the project.

So far, $50 \%$ of the greenhouses with an integrated cooling system have been built. The seedling production lines are installed and functioning. A water basin, for irrigation purposes, has also been dug and is functional to provide water to the production lines. Furthermore, the workforce has been trained to grow seedlings and on the process of grafting. Eventually, the new business started selling seedlings at a low production rate, not yet profitable. No other outputs or outcomes are visible today,

9 All results and listed lessons learned come from the interview with the project leader Karin Kramers. No report has been shared for issues of confidentiality. 
as the whole project development has been hampered by the search for a new partner. Therefore, hardly any data are available today and lessons learned are very limited.

\section{Lessons learned}

\section{Competitiveness}

- Rules and regulations differ from one country to another. Setting up a new venture with sustainability objectives might impact negatively its competitiveness against other competitors in the national value chain but also internationally. Setting up too many boundaries or being too strict on sustainability objectives might threaten the resilience and sustainability of the business. For example: biological control in greenhouses vegetable production is, today, identified as an innovative solution. Nonetheless, this is highly controlled due to the fact that some predator species that control other (pest)insects might threaten the biodiversity if they escape the greenhouse. Although some companies try to look for indigenous species, their work is hampered and the play between responsibility and competitiveness is on. These regulations imposed in the project do not apply to other businesses in the same sector which greatly impact the work and the profitability of such projects as well as the resilience of the business after the project.

Innovation and adaptability

- Having tailor-made innovations, capacities or even businesses, work out well. Presenting adapted solutions to potential beneficiaries to cope with specific characteristics or specific work conditions. Soil Care, a Dutch company, built a fertilizer production site and laboratory within the country of work. Farmers were able to send their soil samples for analysis. Soil Care mixed the soil samples with fertilizer to match specific field parameters to create an optimal soil for each condition.

\section{Exit strategy}

- In this PSI project, the applicant (the country's foreign company) generally does not have the capacity to remain permanently in the country. As the applicant visits once or twice a year, they are sometimes late to identify problems or make decisions on time. It is therefore favourable to have a manager on the ground permanently, who can observe what is happening. This can stimulate better decision making processes.

- The sustainability of businesses created in PSI projects rely on 3 main points:

- Partnering with a good local entrepreneur is crucial as he/she knows "how to get things done" in his/her own country, although the knowledge comes from the Netherlands, the work is done locally.

- The local partner must be able to sustain the business created after the end of the PSI project. Therefore, knowledge transfer at all levels from top management to "core work" (in this case seedling raising) during the PSI project is key.

- To be resilient and sustainable over time, the created business must be innovative and the market well identified. Bringing services already accessible and affordable in the country will not bring any added value to potential consumers, hindering results of the joint venture. 


\section{Drops4crops}

The Drops4Crops projects focuses on the implementation of integrated water resource management measures and efficient water use in water-challenged North Burkina where a major part of the population lives below the poverty line. By implementing these measures, the project aims to support vegetable farmers by bringing production water and particularly off-season to increase horticultural productions. In addition, a package of various services such as credits for farm investments, climatesmart agricultural trainings and secured land access to small holder vegetable farmers, including women, was implemented.

The project started on the $1^{\text {st }}$ of September 2018 and will last 7 years. The project relies on a PublicPrivate Partnership (PPP): private parties consist of 1,500 farmers being part of the ASPMY (Association des Producteurs Maraichers du Yatenga) and its cooperative members (around 30 of them), some of them being single businesses, others, larger ones. Public bodies are represented by the DREA (Direction Régionale de I'Eau et de I'Assainissement) and the DRAAH (Direction Régionale de I'Agriculture et des Aménagements Hydrauliques). There is an interest from private parties to focus on water productivity, especially for improved agricultural productivity and integrated water resource management. The public interest concentrates on natural resource protection as well as poverty alleviation through appropriate and sustainable water use ${ }^{10}$.

In the Drop4Crops project, there are 5 working packages:

1. Access to water: through investments and the development of 142 water points, farmers enjoy an improved access to production water.

2. Integrated Water Resource Management: the first Water Use Management Plan has been defined with the involvement of various stakeholders for an efficient production-water use.

3. Increased water efficiency and productivity: Introduction of new practices and technologies to farmers is done through demonstration farms. Farmers have shown interest to invest in new technologies for more efficient water use, but more productivity measures are necessary to determine the real added-value of the technologies introduced.

4. Access to land: there was quite a big attention towards female producers, how to register lands and exploit them efficiently. Focus group discussions have shown that female-headed households are usually poorer and decision-making at a farm gate in male-headed households are imbalanced towards women. Working specifically with women will help farms and households to become more resilient to phenomena such as climate change or dry climates.

5. Marketing: through the introduction of new technologies and practices the turnover of ASPMY has increased as well as the production.

More than 140 water points have been built and developed on the ground, and farmer communities are now benefiting from an improved access to production water (working package 1). The use of this production water has supported work in other working packages, particularly in package 3 . Increased production and turnover rates have been observed. Although the onion prices were low, the ASPMY turnover rate has increased thanks to a production of 2,300 t onions and $347 \mathrm{t}$ potatoes.

The introduction of new technologies raised interest among farmers who were, later on, eager to learn more about these new technologies. This was unforeseen in a vulnerable and traditional African area where few resources are available and supposedly where the willingness to invest in new technologies remains low.

Eventually, the development of the cooperative itself was an achievement. Structuring cooperatives within the bigger cooperative by sharpening (defining, specifying) the services to members (what they can expect and what does it cost) was an important step. This helped a lot to improve business relations and transactions.

10 All results and listed lessons learned come from the interview with the project leader Wim Simonse. No report has been shared for issues of confidentiality. 


\section{Lessons learned}

\section{Profitability}

- The use of available production water alongside the implementation of better agricultural practices has helped to raise the productivity and the profitability of the cooperative.

- Organized farmers through cooperatives can bring positive impact to their members. For the members of this project, relevant services were offered to the members including access to market, inputs, finance and access to water. This brought sustainable income to the cooperative.

\section{Innovation and adaptability}

- Exposure through demonstrations requires a lot of organization and follow-up. Capacity building expenses are higher than expected, but capacity building is still the best way forward. although demonstrations are small and quite demanding, they are a very important tool to bring many aspects together.

- Asking contribution and resources from cooperatives enables a good basis for the entire project and provide a good environment to make decisions. Referring to the last point, building a trustworthy environment by being transparent also ensures a better commitment of the cooperative members.

- Business development is a key factor: every service (e.g. warehousing) helps to bring added value. When farmers see the added value they are eager to invest.

Sustainability

- Investing in the development of water points and the development of the first Water Use Management Plan has brought access to production water for vegetable producers. If managed correctly, these farmers will be able to sustain and increase their activity. Alongside the introduction of improved farming practices, this could be beneficial to the farmers in the long run.

\section{Inclusiveness}

- The project leader really believes in the success of the project set-up with the RVO concept of PPP stating distinctions in public and private interests in public goods but working by linking them (although the differences in interests).

- Access to land: this was framed before the project and contextualized. Before it was a man issue, but with a quite pragmatic approach and key actors, working at the right moment, the eagerness and willingness to cooperate for an improvement of the vegetable production was visible. At the beginning there were risks that men would not be willing to accept working on it. However, now, access titles for land use are allocated to female farmers. When the right approach is applied, with the right people and with the right attitude, a lot can be achieved.

\section{Transparency}

- It is important to structure the cooperation as a business oriented service delivery organization, defining very specifically what farmers can expect from it. Being transparent is a token for trust between actors. 


\section{SEVIA Tanzania}

The vegetable production today is dominated by small-scale commercial farmers (around 70\%) who have a limited access to good quality inputs, lack of information and knowledge as well as access to national and international output markets. Practices are considered as traditional, leaving room for improvement in terms of productivity, quality and profitability to the farmers. Therefore, the Dutch vegetable (seed) sector could play a role in increased vegetable production in Tanzania and thereby contribute to address issues such as poverty, food insecurity and malnutrition.

SEVIA is a public-private partnership between the Dutch Ministry of Foreign Affairs, Wageningen University and Research and two vegetable breeding companies East-West Seed and Rijk Zwaan. The main objective of SEVIA is to contribute to the development of the vegetable sector in Tanzania and thereby strengthen food security and alleviate poverty. The project tries to address these objectives through two main components:

1. The development of a breeding programme in a public-private partnership with the two Dutch breeding companies to improve the African vegetable varieties and develop adapted-external vegetables (non-traditional African vegetables) to the Tanzanian agro-climatic conditions;

2. The dissemination of Good Agricultural Practices among farming communities in order to increase the productivity and farmers' income in various districts of Tanzania through the deployment of a vegetable "brigade" of extension officers.

Through the introduction of better agricultural inputs alongside knowledge (to use these inputs in an optimal way), the SEVIA project aims at demonstrating new agricultural practices under real-life conditions to farmers. The end goal is to support the development of the horticultural sector towards a better performance and productivity of smallholder farmers through the adoption of Good Agricultural Practices and more modern techniques and technologies.

SEVIA, on its training centre, is testing East-West Seed and Rijk Zwaan varieties, developing demonstration plots and organizing farmer field days to demonstrate modern and good agricultural practices in the vegetable production. African foreign workers (Uganda, Nigeria) in the vegetable sector were also invited on SEVIA site to receive training on vegetable production, SEVIA centre being an interesting example of WUR work in Africa. SEVIA field staff, spread around the country, is organizing demonstration on farmers' plots as well as Training of Farmers (private extension services) on the following topics: crop and variety selection, use of good quality seeds, land selection and preparation, crop management, fertilization, water management or farm economics. Following the words of the manager director, "What started as a rag-tag team of mostly fresh graduates and a few seniors evolved into an "army"." SEVIA largely went beyond its targets and is now about to become economically viable and sustainable. The training centre built for this project will continue with knowledge transfer activities in the future, placing it as a hub of vegetable production training, while some of the staff is slowly integrated to extension teams of the different seed companies involved.

Data collection has demonstrated that adoption is already happening (see table below), although it is variable according to the different locations, farmers' circumstances and technologies introduced, and that it has been beneficial to the farmers knowing the number of good farmer stories coming from the field.

Table Results of adoption rates per technology

\begin{tabular}{lll} 
Area: Meru(Tanzania) & $\begin{array}{l}\text { Adoption rate before intervention } \\
(\%)\end{array}$ & $\begin{array}{l}\text { Adoption rate after intervention } \\
(\%)\end{array}$ \\
Use of improved seeds & 18 & 48 \\
\hline $\begin{array}{l}\text { Crop selection according to the market } \\
\text { demand }\end{array}$ & 38 & 61 \\
\hline Mulching & 0 & 2 \\
\hline Drip irrigation & 0 & 3 \\
\hline Trellising & 35 & 83 \\
\hline Adoption of greenhouse production & 0 & 9 \\
\hline
\end{tabular}

Source: SEVIA (personal communication) 


\section{Lessons learned}

Competitiveness and profitability

- Direct technical support and adoption of improved practices led to improvements in farmers' performance. Farmers were able to increase the productivity (yields and quality) as well as their income. The increased income was then re-invested in their farming activities and livelihoods. For example, some farmers started an off-farm moto-taxi business, built brick houses and dug a borehole that benefited the entire community. The re-investments in farming activities where, for example, buying new greenhouses or drip irrigation equipment.

- Adopting Good Agricultural Practices is key, to raise productivity and optimally use inputs such as high-quality seeds. Therefore, investing in knowledge transfer alongside the development of better and adapted seeds, forms a perfect bridge between seed companies and farmers.

- In the SEVIA project, the breeding programme for both East-West Seed and Rijk Zwaan seed companies was paid for by the companies; while the knowledge transfer activities financed by the project. The development of high-quality seeds, adapted to the local conditions, is widely recognized today as a potential solution to raise farmers' productivity and profitability. Nonetheless, the use of high-quality seeds alone does not guarantee high yields.

Innovation and adaptability

- Training of Trainers with focus on both technical and soft skills contributes to a better dissemination of knowledge to farmers. The SEVIA extension team was, able to demonstrate Good Agricultural Practices and created a learning process among farmer communities. This knowledge transfer activities combined with the introduction of better technologies has shown impactful results, on the field and in end-beneficiary Evidence-based extension is a good mechanism for the adoption of Good Agricultural Practices in farming communities, and more generally, for the transformation of the vegetable production sector. "Seeing is believing", a motto used by SEVIA.

- The work of the field officers also relies on "key farmers", the innovators, the first ones who adopted the promoted practices in different communities. Supported by the field officers, these key farmers set up demonstration plots comparing traditional and improved practices. Without these key farmers, field officers are sometimes facing difficulties to convince other farmers due to a limited trust in extension officers. The peer-to-peer learning approach is considered crucial for convincing other farmers and, in general, adopt the promoted practices.

- One of the limitations in the adoption of better practices is that smallholder farmers often have a rather limited capital, if existing, to invest in their farming activity. Therefore, introducing simple practices and technologies that are easily applied, is essential to convince farmers to implement them and facilitate their adoption.

- The age of the farmers is also having an influence on the adoption rate of new technologies, as young farmers are more attracted to them.

\section{Transparency}

- It seems necessary to work with different organizations, such as TAHA (Tanzania Horticultural Association), or companies. Farming is a business: growing vegetables efficiently is important but not sufficient if there are no markets. Bringing expertise from other actors is crucial to provide good recommendations to farmers and to meet their needs. For example, TAHA collects extensive data on prices and stocks of agricultural commodities in all regions of Tanzania. TAHA also has a commercial branch which buys produce from farmers. This could help them in their marketing and planning.

- SEVIA was able to create a flow of information through Tanzania, where access to information is a major bottleneck for farmers.

\section{Other learnings}

- Establishing and maintaining relations with the local authorities and leaders may bring some bureaucratic problems and delays, but is still crucial for several reasons. First, transparency with local authorities facilitates the implementation of the project in a given place. Second, when the project is supported by local authorities, it contributes to better acceptance and trust of farmers in the programme. 
Wageningen Centre for Development Innovation

Wageningen University \& Research P.O. Box 88

6700 AB Wageningen

The Netherlands

$\mathrm{T}+31(0) 317486800$

www.wur.eu/cdi

Report WCDI-20-115
Wageningen Centre for Development Innovation supports value creation by strengthening capacities for sustainable development. As the international expertise and capacity building institute of Wageningen University \& Research we bring knowledge into action, with the aim to explore the potential of nature to improve the quality of life. With approximately 30 locations, 5,000 members of staff and 12,000 students, Wageningen University \& Research is a world leader in its domain. An integral way of working, and cooperation between the exact sciences and the technological and social disciplines are key to its approach. 



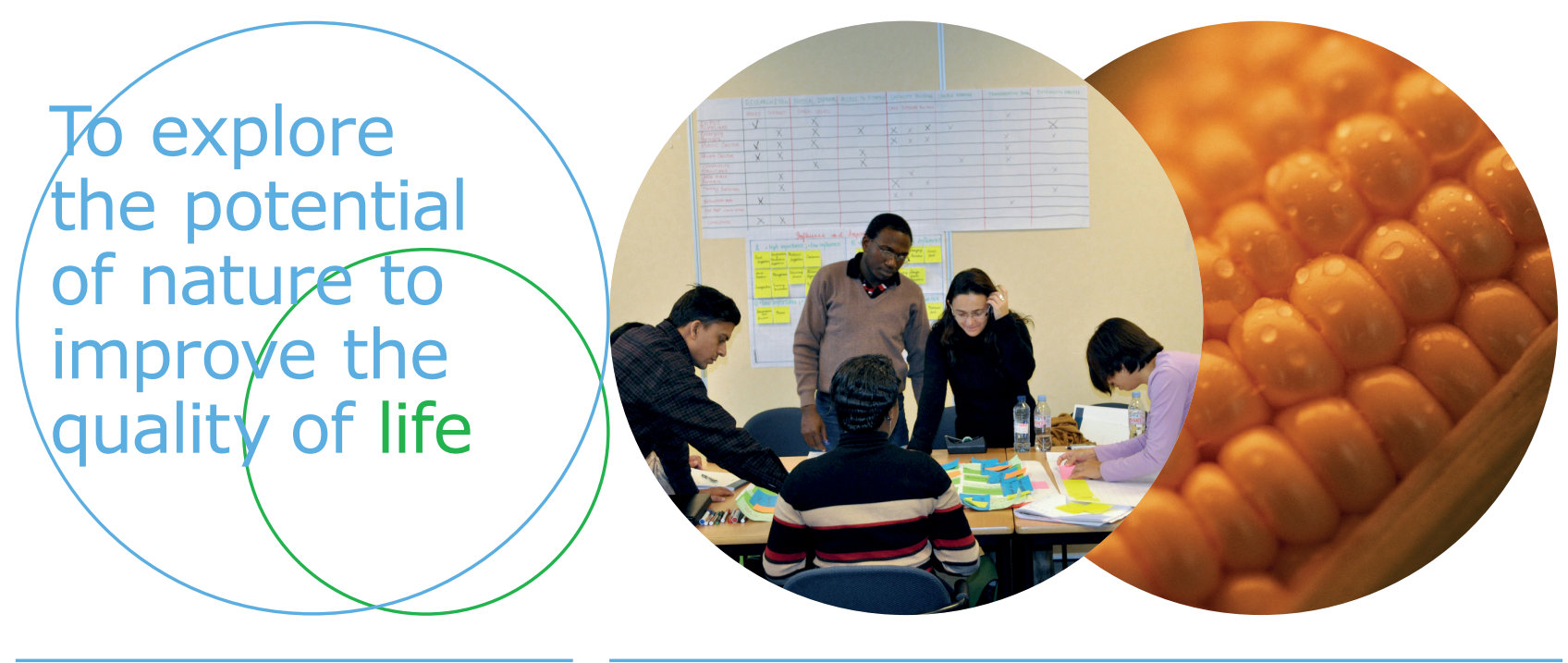

Wageningen Centre for Development Innovation Wageningen University \& Research P.O. Box 88 6700 AB Wageningen The Netherlands T +31 (0)317486800 www.wur.eu/cdi

Report WCDI-20-115
Wageningen Centre for Development Innovation supports value creation by strengthening capacities for sustainable development. As the international expertise and capacity building institute of Wageningen University \& Research we bring knowledge into action, with the aim to explore the potential of nature to improve the quality of life. With approximately 30 locations, 5,000 members of staff and 12,000 students, Wageningen University \& Research is a world leader in its domain. An integral way of working, and cooperation between the exact sciences and the technological and social disciplines are key to its approach. 